\title{
Moesin and myosin phosphatase confine neutrophil orientation in a chemotactic gradient
}

\author{
Xiaowen Liu, ${ }^{1 *}$ Tao Yang, ${ }^{3 *}$ Koya Suzuki, ${ }^{4}$ Sachiko Tsukita, ${ }^{4}$ Masaru Ishii,,${ }^{5}$ \\ Shuping Zhou, ${ }^{3}$ Gang Wang, ${ }^{1}$ Luyang Cao, ${ }^{1}$ Feng Qian, ${ }^{1}$ Shalina Taylor, ${ }^{1}$ \\ Myung-Jin Oh, ${ }^{2}$ Irena Levitan, ${ }^{2}$ Richard D. Ye, ${ }^{1}$ Graeme K. Carnegie, ${ }^{1}$ \\ Yong Zhao, ${ }^{3}$ Asrar B. Malik, ${ }^{1}$ and Jingsong $\mathrm{Xu}^{1}$ \\ 'Department of Pharmacology and 2Department of Medicine, University of Illinois, Chicago, IL 60612 \\ ${ }^{3}$ State Key Laboratory of Biomembrane and Membrane Biotechnology, Institute of Zoology, Chinese Academy of Sciences, \\ Beijing 100101, China \\ ${ }^{4}$ Laboratory of Biological Science and ${ }^{5}$ Laboratory of Cellular Dynamics, Graduate School of Medicine, Osaka University, \\ Suita 565-0871, Osaka, Japan
}

\begin{abstract}
Neutrophils respond to invading bacteria by adopting a polarized morphology, migrating in the correct direction, and engulfing the bacteria. How neutrophils establish and precisely orient this polarity toward pathogens remains unclear. Here we report that in resting neutrophils, the ERM (ezrin, radixin, and moesin) protein moesin in its active form (phosphorylated and membrane bound) prevented cell polarization by inhibiting the small GTPases Rac, Rho, and Cdc42. Attractant-induced activation of myosin phosphatase deactivated moesin at the prospective leading edge to break symmetry and establish polarity. Subsequent translocation of moesin to the trailing edge confined the formation of a prominent pseudopod directed toward pathogens and prevented secondary pseudopod formation in other directions. Therefore, both moesin-mediated inhibition and its localized deactivation by myosin phosphatase are essential for neutrophil polarization and effective neutrophil tracking of pathogens.
\end{abstract}

\section{CORRESPONDENCE \\ Jingsong Xu: \\ jingsong@uic.edu \\ OR \\ Yong Zhao: \\ zhaoy@ioz.ac.cn}

Abbreviations used: CI, chemotaxis index; DIC, differential interference contrast; ERM, ezrin, radixin, and moesin; GEF, guanine nucleotide exchange factor; i.t., intratracheal(ly); LSR, local Shwartzman reaction; MBS, myosin-binding subunit; MLC, myosin II light chain; MPO, myeloperoxidase; PRG, PDZRhoGEF; PTX, pertussis toxin; RhoGDI, Rho GDP-

dissociation inhibitor.
Neutrophils are the first line of host defense against invading pathogens. To kill invading pathogens, neutrophils must attach to the blood vessel walls, transmigrate into tissues, reach the site of infection (via chemotaxis), and phagocytose pathogens (Kolaczkowska and Kubes, 2013). Neutrophil polarization and directional sensing induced by attractants from both pathogens and the host are two critical events during the pursuit of pathogens by neutrophils. In neutrophils, attractant-induced polarization depends on two opposing pathways, termed the "frontness" and "backness" pathways, that diverge from the same attractant receptor (Xu et al., 2003). The frontness and backness signals are mediated by distinct trimeric $\mathrm{G}$ proteins. Gi activates the small GTPase Rac and phosphatidyl-inositol-3,4,5Tris-phosphate (PIP3), which are responsible for pseudopod formation. G12/13 triggers a second GTPase, RhoA, and myosin II to form the uropod (Xu et al., 2003). This mutually inhibited frontness and backness regulation provides a

Dr. Carnegie died on 20 July 2014.

*X. Liu and T. Yang contributed equally to this paper. mechanochemical explanation for the ability of neutrophils to polarize in the presence of a uniform attractant (chemokinesis). However, this model does not provide mechanisms for how neutrophils precisely orient their polarity toward invading bacteria.

In addition to the frontness-backness model, other models based on the reaction-diffusion paradigm (Turing, 1952) have been adopted to describe the chemotactic behaviors of cells, including a "local self-enhancing reaction, longrange inhibition" (Meinhardt and Gierer, 1974, 2000; Meinhardt, 1999), "local excitation-global inhibition" (Parent and Devreotes, 1999; Ma et al., 2004; Swaney et al., 2010), and "lateral pseudopod inhibition" (Firtel and Chung, 2000). In each of these models, cells use localized activation (or self-enhancement) coupled with long-range inhibition to sense the gradient and establish polarity. Localized activation has been

2015 Liu et al. This article is distributed under the terms of an AttributionNoncommercial-Share Alike-No Mirror Sites license for the first six months after the publication date (see http://www.rupress.org/terms). After six months it is available under a Creative Commons License (Attribution-Noncommercial-Share Alike 3.0 Unported license, as described at http://creativecommons.org/licenses/ by-nc-sa/3.0/). 
specifically implicated in the regulation of pseudopod formation (Swaney et al., 2010). Despite the importance of localized activation for cell polarization, the molecules that initiate cell polarization are still unknown (Swaney et al., 2010). Long-range inhibition is thought to be exerted by a fast diffusible global inhibitor, which is generated through localized activation and diffuses into the rest of cell (Meinhardt, 2009). The classical function of a global inhibitor is to allow only one prominent leading edge to form (usually oriented toward the source of attractant) while preventing inefficient secondary pseudopod formation in other directions. However, after decades of intense research, there is still no experimental evidence of such a global inhibitor. Although backness signals such as RhoA and myosin II are recruited to the trailing edges and locally inhibit frontness signals, they are not the theoretical global inhibitors because they do not turn off attractant-induced backness signals (Xu et al., 2003). Instead, the activation of both the frontness and backness signals is considered to be a localized form of activation driven by receptor ligation (Narang, 2006). A recent report indicates that membrane tension, rather than diffusion-based inhibition, is responsible for long-range inhibition (Houk et al., 2012). Although both backness signals and membrane tension play important roles in preventing secondary pseudopod formation in chemokinesis, whether they play similar roles in directed cell migration (chemotaxis) remains unknown.

The ezrin, radixin, and moesin (ERM) proteins are crucial components for linking the actin cytoskeleton to the plasma membrane. Importantly they also participate in signal transduction (Bretscher et al., 2002). The ERM proteins can reciprocally regulate the small Rho GTPases through interaction with Rho guanine nucleotide exchange factors (GEFs [RhoGEFs]), Rho GTPase-activating proteins (RhoGAPs), and Rho GDPdissociation inhibitors (RhoGDIs; Hirao et al., 1996; Takahashi et al., 1997; Tolias et al., 2000; Hatzoglou et al., 2007; Valderrama et al., 2012). Moesin is the predominant ERM protein isoform in leukocytes such as neutrophils (Ivetic and Ridley, 2004). Moesin activity is self-inhibited by an intramolecular interaction between its $\mathrm{N}$ - and C-terminal domains, which upon activation bind to transmembrane proteins and the actin cytoskeleton, respectively (Reczek et al., 1997; Serrador et al., 1997; Yonemura et al., 1998). Activation of moesin is initiated by binding to PIP2 and stabilized by conserved phosphorylation at Thr558 (Hirao et al., 1996; Yoshinaga-Ohara et al., 2002). Upon attractant stimulation, neutrophils and lymphocytes polarize and migrate concurrently with the rapid dephosphorylation of moesin (Yoshinaga-Ohara et al., 2002; Brown et al., 2003; Lee et al., 2004; Martinelli et al., 2013). This dephosphorylation of moesin is mediated by myosin phosphatase, which consists of a catalytic subunit (protein phosphatase $1 \mathrm{c}$ [PP1c]), a myosin-binding subunit (MBS), and a small subunit (Fukata et al., 1998; Kawano et al., 1999). In neutrophils, myosin phosphatase interacts with a front signaling molecule, the hematopoietic protein 1 (Hem-1; Weiner et al., 2006). How myosin phosphatase and moesin might regulate neutrophil chemotaxis remains unclear.
Here, we report that moesin was found to be required for the neutrophil chasing of invading pathogens, which allowed the formation of one prominent pseudopod extending toward the source of the attractant (e.g., bacteria) and prevented pseudopod formation in other directions. Moesin was constitutively active and membrane bound in resting cells and, thus, maintained cell symmetry by restricting the small GTPases Rac, Rho, and Cdc42 from interacting with their GEFs. To break symmetry, the cells used myosin phosphatase (activated via the Gi-Hem1 pathway) to terminate moesin-mediated inhibition at the would-be leading edges and initiated cell polarization and migration. Removal of moesin not only enhanced the activity of small Rho GTPases Rac, Rho, and Cdc42 but also induced cell protrusion in the wrong direction and thereby abolished the ability of the cells to catch bacteria. Furthermore, inhibition of these moesin-regulated GEFs fully or partially rescued the moesin-depleted phenotypes. Therefore, the inhibition-activation mechanism conferred by moesin and myosin phosphatase is critical for neutrophil polarization and orientation toward invading bacteria.

\section{RESULTS \\ Deletion of moesin impairs neutrophil-mediated microbial killing and inflammation}

To address the role of moesin in neutrophil-mediated microbial killing and inflammation, we monitored the killing of bacteria in mouse lungs after inducing pneumonia using Pseudomonas aeruginosa strain 103 (PA103) through intratracheal (i.t.) injection. We observed an augmented load of $P$ aeruginosa in moesin knockout $\left(\mathrm{Msn}^{-/ Y}\right)$ lungs compared with WT lungs (Fig. 1 A; P < 0.01). Approximately $88 \%$ of the total $2 \times 10^{5}$ bacteria injected were killed in WT lungs, whereas only $\sim 26 \%$ were killed in $M s n^{-/ Y}$ lungs (Fig. 1 B). To assess direct microbial killing by neutrophils, we isolated $\mathrm{Msn}^{-/ Y}$ neutrophils and performed bacterial killing in vitro. Compared with WT neutrophils, $\mathrm{Msn}^{-/ Y}$ neutrophils showed a significantly reduced microbial killing ability (Fig. 1 C; P < 0.01).

We also determined the function of moesin in neutrophilmediated vascular inflammation using the modified local Shwartzman reaction (LSR; Brozna, 1990; Qian et al., 2009). The vascular inflammation induced during the LSR is mediated by neutrophils, as depletion of neutrophils prevents tissue injury (Qian et al., 2009). The dorsal skins of WT and $\mathrm{Msn}^{-/ Y}$ mice were first injected s.c. with either $80 \mu \mathrm{g}$ LPS (Fig. 1 D, right side of each panel) or PBS as a control (Fig. 1 D, left side of each panel). After $24 \mathrm{~h}$, either $0.2 \mu \mathrm{g}$ TNF or the same volume of PBS was injected s.c. into the site receiving LPS. We observed skin lesions resembling thrombohemorrhagic vasculitis, with visible hemorrhage and dermal tissue necrosis at the injection site (Fig. 1 D, right side of each panel). However, $M s n^{-/ Y}$ mice showed reduced vascular inflammation and injury compared with the WT (Fig. 1, D and E). Additionally, significantly decreased neutrophil accumulation at the LPS injection site was observed in $M s n^{-/ Y}$ mice compared with WT mice, as measured via tissue myeloperoxidase (MPO) 

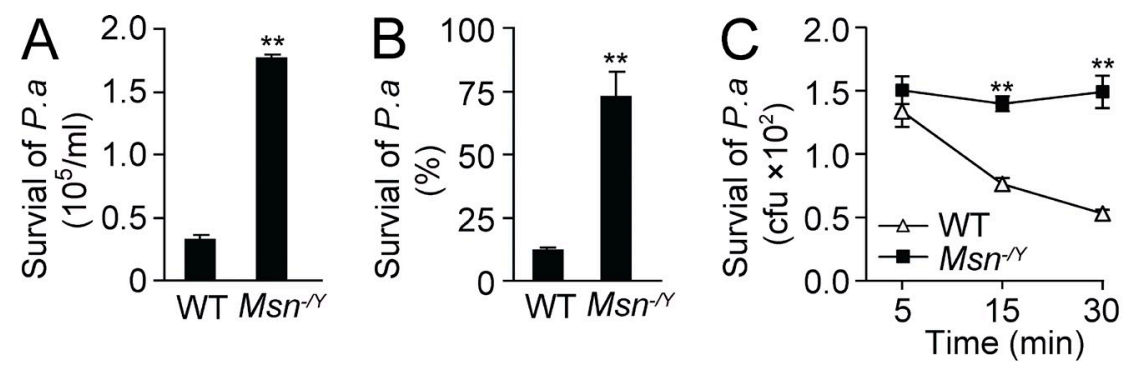

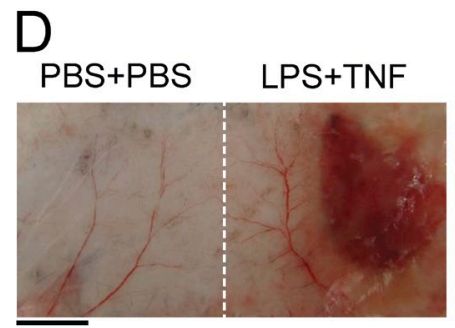

WT

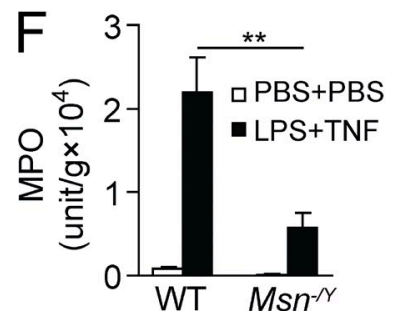

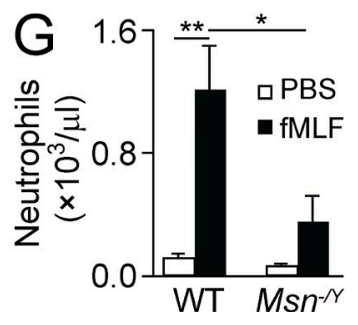

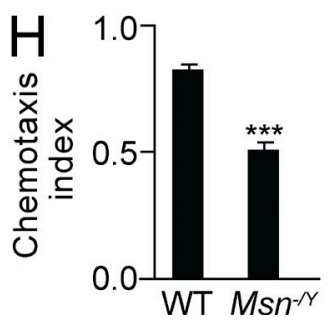

Figure 1. Moesin regulates neutrophil microbial killing and inflammation. (A and B) WT and moesin knockout ( $\mathrm{Msn}^{-/}$) mice were i.t. injected with $P$. aeruginosa $(2 \times$ $\left.10^{5}\right) .8 \mathrm{~h}$ later, lungs were isolated, and the number (A) and percentage (B) of surviving colonies derived from lysates were determined. (C) WT and $\mathrm{Msn}^{-/ Y}$ neutrophils were incubated with opsonized $P$. aeruginosa for the indicated times, and surviving colonies were determined. $(A-C){ }^{* *}, P<0.01$ compared with WT (Student's $t$ test). (D-F) Microvascular injury was induced in a classical LSR by consecutive injections of $80 \mu \mathrm{g}$ LPS and then $0.2 \mu \mathrm{g}$ TNF or PBS as controls. (D) Macroscopic appearance of dorsal skin in WT and $\mathrm{Msn}^{-/ \gamma}$ mice after LSR. Bar, $5 \mathrm{~mm}$. (E) The degree of hemorrhage in the WT and $\mathrm{Msn}^{-1 Y}$ mice in D was estimated based on densitometry analysis of skin samples receiving either LPS or PBS injection. Results are shown as the ratio of the value with LPS versus the value with PBS. ${ }^{* *}{ }^{*} \mathrm{P}<$ 0.001 (Student's $t$ test). (F) Tissue MPO activities in skins were measured and normalized by tissue weight. Data are presented as V-Max value/g tissue. ${ }^{* *}, \mathrm{P}<0.01$ (Student's $t$ test).

(G) WT or $\mathrm{Msn}^{-/ Y}$ mice were i.p. injected with $10 \mathrm{nM} \mathrm{fMLF}$, and neutrophil emigration into the peritoneal cavity was assessed after $4 \mathrm{~h}$. For all groups, $n=3-4$ mice. ${ }^{*}, \mathrm{P}<0.05 ;{ }^{* *}$, $\mathrm{P}<0.01$ (Student's $t$ test). (H) WT and Msn ${ }^{-/ Y}$

neutrophils were exposed to a 10-nM fMIFL gradient, and $\mathrm{Cl}$ was calculated by the ratio of net migration in the correct direction to the total migration length. ${ }^{* *}, \mathrm{P}<0.001$ compared with WT (Student's $t$ test). Data are representative of (D) or are compiled from (A-C and E-H) three independent experiments (mean and SEM in A-C and $\mathrm{E}-\mathrm{H}$ ).

activity (Fig. $1 \mathrm{~F} ; \mathrm{P}<0.01$ ). Thus, deletion of moesin inhibited neutrophil microbial killing and neutrophil-mediated vascular inflammation.

\section{Moesin is required for neutrophil infiltration and chemotaxis}

The decreased bacterial clearance and inflammation in $\mathrm{Msn}^{-/ Y}$ mice described above may result from decreased neutrophil infiltration. Therefore, we studied bacterial formyl peptide fMet-Leu-Phe (fMLF; $10 \mathrm{nM}$ )-induced mouse neutrophil infiltration into the peritoneal cavity in vivo. WT and $\mathrm{Msn}^{-/ Y}$ mice were injected with either saline or $10 \mathrm{nM}$ fMLF. After $4 \mathrm{~h}$, peritoneal neutrophils were recovered and counted. fMLF substantially induced neutrophil transmigration into the peritoneal cavity in WT mice (Fig. 1 G). However, $\mathrm{Msn}^{-/ Y}$ neutrophils showed markedly reduced transmigration as compared with the WT cells (Fig. 1 G).

Next, we determined whether moesin regulates neutrophil adhesion and migration, which are both required for neutrophil tissue infiltration. We isolated $M s^{-/ Y}$ neutrophils and tested their adhesive and chemotactic behaviors in vitro. Interestingly, deletion of moesin did not affect neutrophil adhesion to WT mouse lung vascular endothelial cells (not depicted). When applied to a chemoattractant concentration gradient generated by the EZ-Taxiscan device, we observed that WT neutrophils migrated up the gradient with fewer turns, whereas $M s n^{-/ Y}$ neutrophils frequently changed direction and exhibited poor directionality, showing a significantly lower chemotaxis index (CI; the ratio of net migration in the correct direction to the total migration length [Xu et al., 2005]) compared with the WT controls (0.51 vs. 0.83, P < 0.001; Fig. $1 \mathrm{H})$. Thus, $M s n^{-/ Y}$ neutrophils exhibited significantly decreased transmigration in vivo and chemotaxis in vitro.

\section{Distinct activation pattern of moesin and myosin II}

We continued to explore how moesin regulates neutrophil migration and sequestration. Although both moesin and the myosin II light chain (MLC) are localized at the trailing edges of migrating neutrophils (Yoshinaga-Ohara et al., 2002; Xu et al., 2003), we found that they exhibited different translocation and activation patterns. Moesin-YFP (stably expressed in differentiated human promyelocytic leukemia [HL60] cells) localized uniformly around the cell membrane in the resting state and dissociated from the membrane on the side of the cell where the leading edge started to form after fMLF stimulation (Fig. 2 A, top; >100 cells were examined). The remaining membrane-bound moesin localized to the trailing edge and was almost absent from the leading edge (Fig. $2 \mathrm{~A}$, top; the 
A
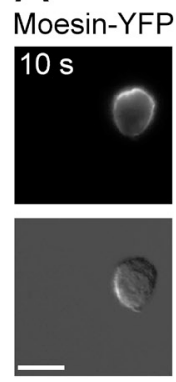

MLC-YFP
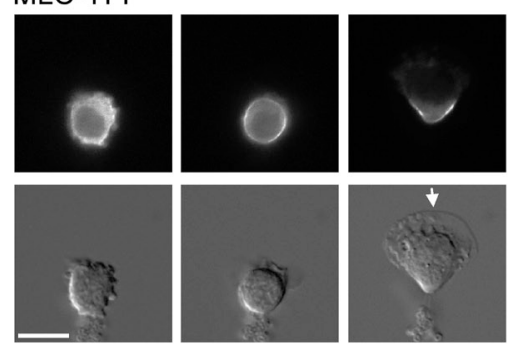

$\mathrm{B}$
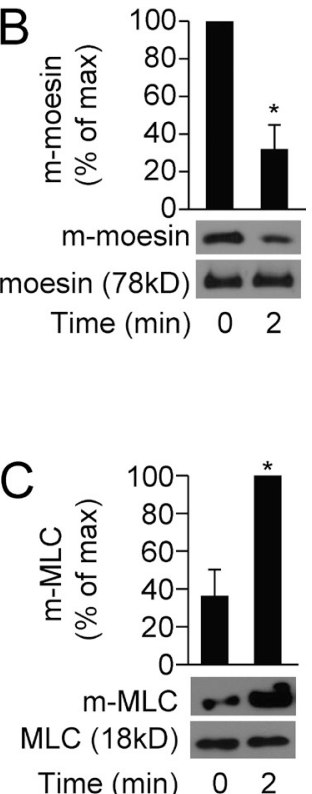

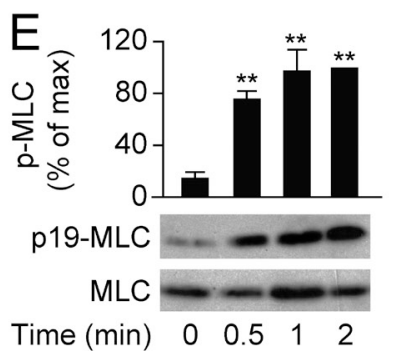

$\begin{array}{llllllllll}\text { Time }(\min ) & 0 & 0.5 & 1 & 2 & \text { Time }(\min ) & 0 & 0.5 & 1 & 2\end{array}$

Figure 2. Differential activation of moesin and MLC. (A) HL6O cells ( $n>30$ per group) expressing moesin-YFP or MLC-YFP were stimulated for the indicated times with $100 \mathrm{nM}$ fMLF and visualized by fluorescence (top rows) and differential interference contrast (DIC) microscopy (bottom rows). Arrows indicate leading edges. Bars, $10 \mu \mathrm{m}$. (B and C) HL60 cells were left untreated or were stimulated with $100 \mathrm{nM} \mathrm{fMLF}$, and quantification of membrane-bound (m-) moesin (B) or m-MLC (C) was evaluated by immunoblot. Levels were quantitated and presented relative to the maximum value. ${ }^{*}, \mathrm{P}<0.05$ compared with the value at basal (Student's $t$ test). (D and E) HL60 cells were stimulated for the indicated times with $100 \mathrm{nM}$ fMLF, and phosphorylated ( $p-$ ) moesin (D) or $p-M L C$ (E) versus total protein levels were assessed by immunoblot. Graph shows quantification of $p$-moesin and $p-M L C$, presented relative to maximum activation of $p$-moesin at 0 min or $p-M L C$ at 2 min. ${ }^{*}, P<0.01{ }^{*}{ }^{* *}, P<0.001 \mathrm{com}-$ pared with the value at $0 \mathrm{~min}$ (Student's $t$ test). Data are representative of ( $A$ and blots in $B-E$ ) or are compiled from three independent experiments (graphs in B-E; mean and SEM in B-E).

time course of moesin translocation to the uropod is quantified in Table S2). Consistent with the dissociation of moesin-YFP from the cell membrane, the levels of membrane-bound moesin and moesin phosphorylation ( $\mathrm{p}$-moesin, active form) were also decreased upon attractant stimulation (Fig. 2, B and D).

In contrast to moesin-YFP, MLC-YFP translocated from the cytosol to the cell membrane and was gradually recruited to the trailing edge after the application of $\mathrm{AMLF}$ (Fig. $2 \mathrm{~A}$, bottom; and Table S2; >100 cells were examined). MLC was activated upon AMLF stimulation, as shown by examining the

levels of membrane-bound MLC and MLC phosphorylation (p-MLC, active form), which were markedly increased after fMLF stimulation (Fig. 2, C and E). Thus, during AMLFinduced neutrophil polarization, moesin was dephosphorylated and dissociated from the cell membrane, where future pseudopods would form and protrude. In contrast, MLC was phosphorylated and recruited to cell membrane from the cytosol.

Next, we addressed the potential regulatory relationship between moesin and MLC by coexpressingYFP-tagged moesin and CFP-tagged MLC in HL60 cells. We again demonstrated that both moesin-YFP and MLC-CFP were localized to the trailing edges of polarized cells stimulated with AMLF (Fig. 3 A, left). To inhibit MLC activity, we treated cells with either the myosin inhibitor blebbistatin $(100 \mu \mathrm{M}, 30 \mathrm{~min})$ or the Rho kinase inhibitor Y27632 (10 $\mu \mathrm{M}, 30 \mathrm{~min})$. Upon uniform stimulation of AMLF, these inhibitor-treated cells formed multiple pseudopods in the earlier stage and gradually formed a single prominent pseudopod and a long tail, as reported previously (Xu et al., 2003). As expected, MLC-CFP showed reduced membrane localization and was more uniformly distributed in cells treated with either of the inhibitors (Fig. $3 \mathrm{~A}$, middle and right panels in the third row). However, moesin-YFP remained associated with the cell membrane in these long tails (Fig. $3 \mathrm{~A}$, middle and right panels in the second row; the distributions of both MLC and moesin over time are shown in Table S3). Thus, inhibiting MLC activity caused MLC to be uniformly distributed but did not alter the attractant-induced localization of moesin at the trailing edge.

To determine whether moesin regulates MLC localization, we transfected Discosoma sp. red fluorescent protein (DsRed)tagged MLC into both control and moesin RNAi-treated cells (Fig. 3 B; the RNAi constructs were tagged with GFP). We observed that MLC-DsRed translocated to the uropod in control cells after fMLF stimulation (Fig. 3 C, left) but was more uniformly distributed in moesin RNAi cells (Fig. 3 C, right; the quantification of MLC localization in both cell lines over time is shown in Table S4).

\section{Moesin determines cell orientation toward pathogens or in a gradient}

Both moesin and MLC localized to the uropods of neutrophils, but they presented distinct translocation and activation patterns, as described above. We determined whether moesin and MLC control cell orientation in a gradient. Untreated control HL60 cells migrated almost directly toward a point source of $10 \mu \mathrm{M}$ fMLF (provided with a micropipette), exhibiting one protrusive pseudopod and one contractile uropod (Fig. 4 A, top; and Video 1). Although Rho kinase inhibitor Y27632treated HL60 cells formed multiple leading edges in a uniform concentration of PMLF (Xu et al., 2003), these cells were still able to form a stable, protrusive pseudopod in a gradient of AMLF and migrated straight toward the tip of the pipette (Fig. 4 A, bottom;Video 2). By tracking the movement of only the pseudopods of the Y27632-treated cells, it was found that the cells exhibited a CI almost identical to nontreated controls (0.76 vs. 0.78; Fig. 4 B). However, Y27632 

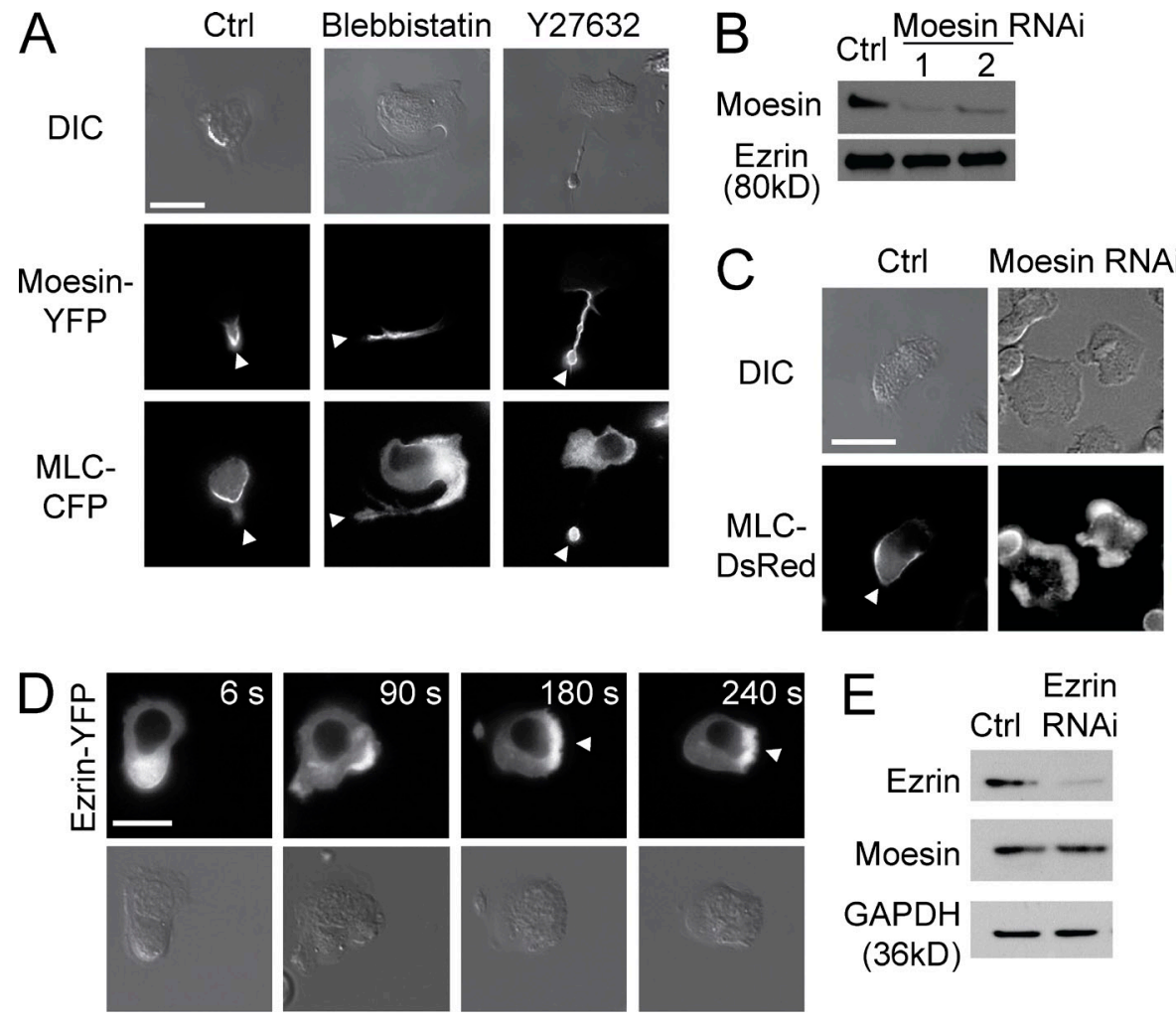

F

Ctrl

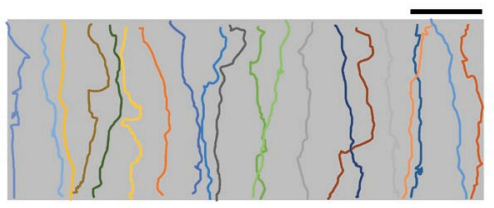

Ezrin

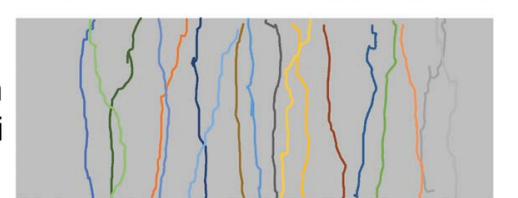

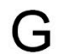

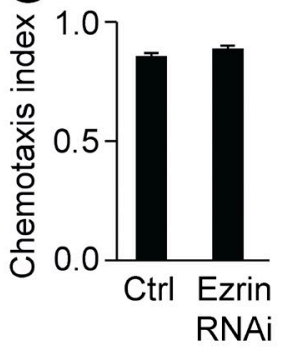

$\mathrm{H}$

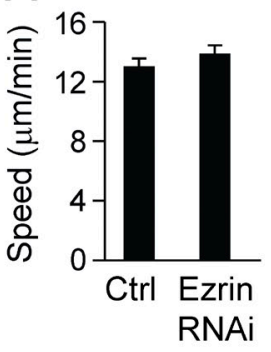

Figure 3. Moesin regulates MLC localization. (A) HL60 cells expressing both moesin-YFP and MLC-CFP were left untreated (left) or were treated with blebbistatin (middle) or Y27632 (right) in the presence of $100 \mathrm{nM}$ fMLF for $2 \mathrm{~min}$. Cells were visualized by DIC (top) and fluorescence microscopy (middle and bottom). (B) Expression of moesin in control cells and moesin RNAi-treated cells was analyzed by immunoblot. Two moesin RNAi-treated cell lines are shown. Ezrin was used as a loading control. (C) Control and moesin RNAi-treated cells expressing MLCDsRed were stimulated with $100 \mathrm{nM}$ fMLF for $2 \mathrm{~min}$, and cells were visualized by DIC (top) and fluorescence microscopy (bottom). (A and C) Arrowheads indicate the trailing edges. (D) Cells expressing ezrin-YFP were stimulated with $100 \mathrm{nM}$ fMLF and imaged by fluorescence (top) and DIC microscopy (bottom) at the indicated times. Arrowheads point to the leading edges. (E) Expression of ezrin was assessed in control and ezrin RNAitreated cells by immunoblot. Moesin and GAPDH were used as loading controls. (F) HL60 cells were left untreated (Ctrl) or were treated with ezrin RNAi in an fMLF gradient of $100 \mathrm{nM}$ (>30 cells per condition). Each trace represents the trajectory of one cell. Bars: $(A, C$, and D) $10 \mu \mathrm{m}$; (F) $100 \mu \mathrm{m}$. (G and H) Cells were treated as in $\mathrm{F}$, and $\mathrm{Cl}(\mathrm{G})$ and migration speed $(H)$ were calculated. Data are representative of (A-F) or are compiled from three independent experiments $(\mathrm{G}$ and $\mathrm{H}$; mean and SEM in $\mathrm{G}$ and $\mathrm{H}$ ). severely damaged tail contraction and caused the cells to leave long tails along the AMLF gradient (Fig. 4 A, bottom; and Video 2).

In contrast, moesin RNAi-treated cells were not able to form a single prominent pseudopod pointing to the pipette (Fig. 4 A, middle; and Video 3). These cells presented randomly protruding pseudopods and changed directions frequently, sometimes even migrating down the gradient. Overall, these cells traced circuitous paths and spent more time in deflective directions compared with control cells (Fig. 4 A, middle; and Video 3). Hence, their directional sensing ability was severely damaged, and they showed a significantly decreased CI (0.15 vs. 0.78, P < 0.001; Fig. 4 B) and a much slower speed compared with the controls $(2.0 \mathrm{vs} .5 .0 \mu \mathrm{m} / \mathrm{min}$, $\mathrm{P}<0.001$; Fig. $4 \mathrm{C}$; speed was measured by tracking pseudopod movement). Thus, moesin and not MLC determined cell orientation in an attractant gradient. Similar results were observed under stimulation with a different chemoattractant, IL-8 (Fig. 4 D).

Upon encountering the pathogen Candida albicans, resting control cells polarized and migrated directly toward C. albicans (Fig. 4 E, top). Stable pseudopods protruded in the correct direction (toward the pathogen) and eventually engulfed the pathogen (Fig. 4 E, top; $79 \%$ of 91 cells tested caught the pathogen). In contrast, moesin RNAi-treated cells protruded in random directions when encountering C. albicans, and very few caught the pathogen (Fig. 4 E, bottom; only $\sim 23 \%$ of 78 cells tested caught the pathogens). These observations were consistent with the data obtained in chemical gradients described above.

A small amount of ezrin is expressed in neutrophils ( $~ 10 \%$ of total ERM proteins [Ivetic and Ridley, 2004]). However, we found that the ezrin expression level was not altered in moesin-depleted cells compared with the control (Fig. 3 B). 

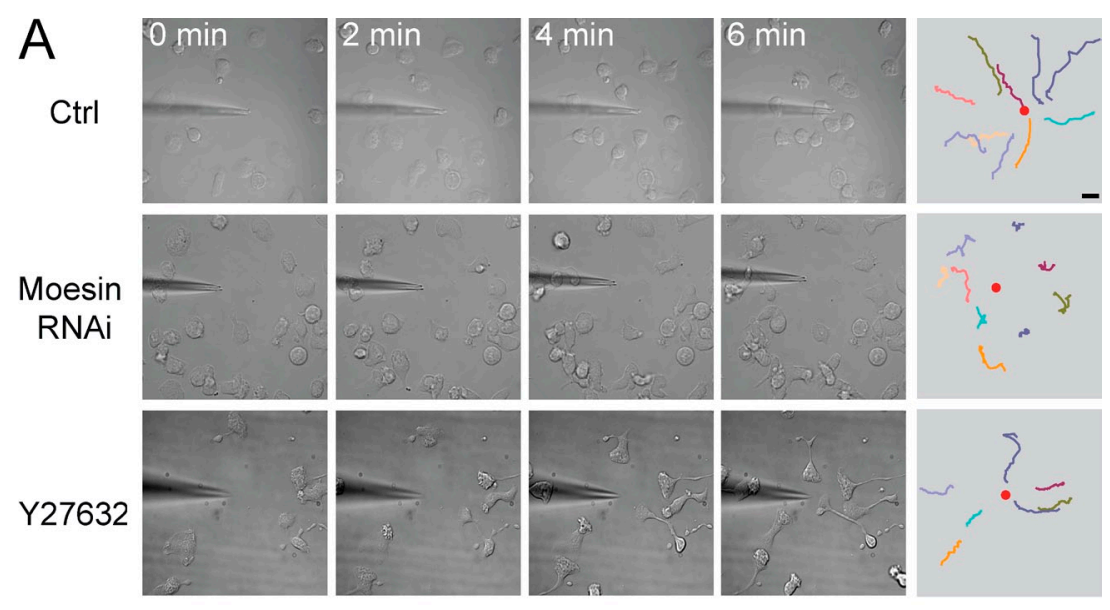

Figure 4. Moesin, and not MLC, is essential for cell orientation. (A) Control HL60 cells (Ctrl; top), moesin RNAi-treated cells (middle), or Y27632-treated cells (bottom) migrated toward a point source of $10 \mu \mathrm{M}$ fMLF. (B and C) Cells were treated as in $\mathrm{A}$, and $\mathrm{Cl}(\mathrm{B})$ and migration speed (C) were calculated. ${ }^{* *}, \mathrm{P}<0.01 ;{ }^{* * *}, \mathrm{P}<0.001 \mathrm{com}-$ pared with control (Student's $t$ test). (D) Control and moesin RNAi cells were exposed to a 10-nM IL-8 gradient, and $\mathrm{Cl}$ was calculated. ${ }^{* *}, \mathrm{P}<0.01$ (Student's $t$ test). (E) Control (top) and moesin RNAi-treated (bottom) cells ( $n>30$ per group) were exposed to C. albicans. (A and E) Bars, $10 \mu \mathrm{m}$. Data are representative of ( $A$ and $E$ ) or are compiled from three independent experiments $(B-D$; mean and SEM in B-D).
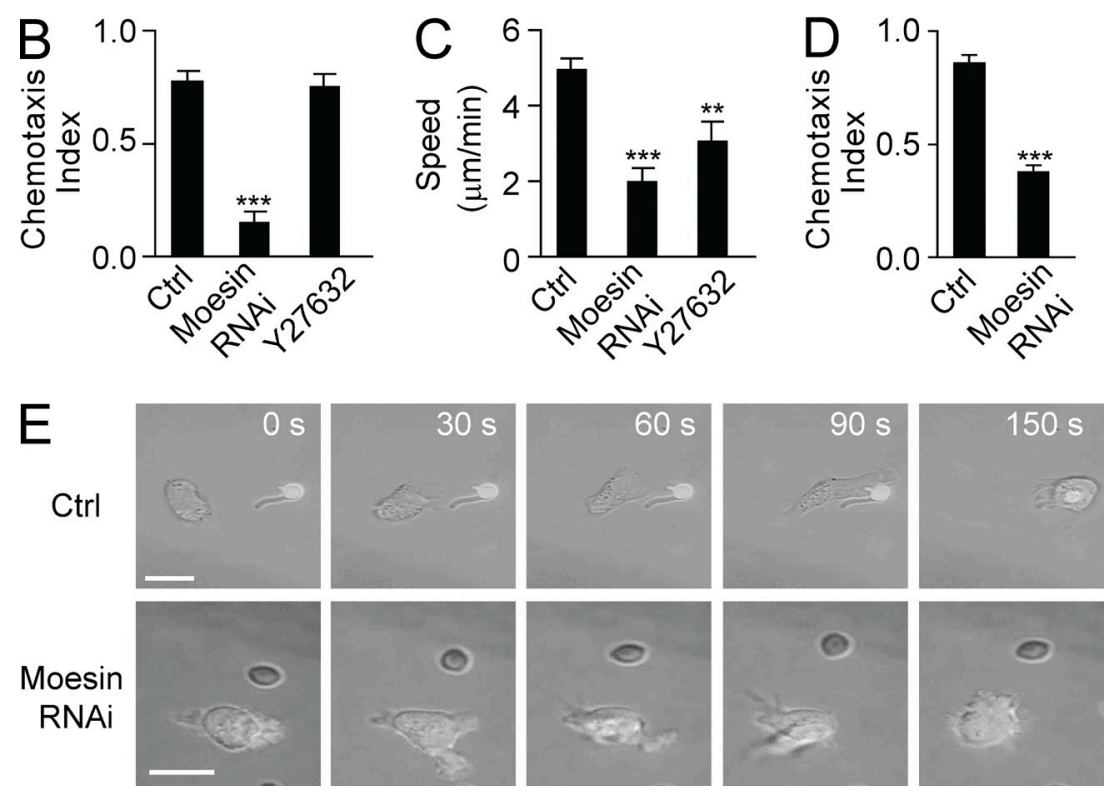

In contrast to the uropod localization of moesin, ezrin translocated to the pseudopod in polarized cells (Fig. 3 D). Furthermore, knockdown of ezrin had little effect on cell migration (Fig. 3, E-H). Thus, ezrin exhibited a different translocation pattern from moesin and did not determine cell orientation during directed neutrophil migration.

\section{Constitutively active moesin inhibits cell migration}

Moesin was deactivated and translocated away from pseudopod (Fig. 2), suggesting that moesin could be an inhibitor of pseudopod protrusion. We therefore predicted that enhancing moesin activity would block cell migration. To test this hypothesis, we stably expressed a YFP-tagged phosphomimetic mutant, moesin-T558D (Thr558 was mutated to Asp), in HL60 cells. Similar to WT moesin-YFP, moesin-T558D-YFP was membrane bound in the resting state but showed very little dissociation from the cell membrane after uniform application of fMLF (Fig. 5 A; >100 cells were examined). We observed that cells occasionally extended transient ruffles, but they were retracted shortly thereafter. Thus, expression of moesin-T558D inhibited cell polarization and migration.

When cells expressing moesin-T558D were exposed to an $\mathrm{AMLF}$ concentration gradient, the cells exhibited unstable migration with poor directionality. The CI was significantly lower in cells expressing moesin-T558D compared with WT controls (0.33 vs. $0.84, \mathrm{P}<0.001$; Fig. 5 B). In contrast, cells expressing moesin-T558A (in which Thr558 is mutated to Ala), which cannot be phosphorylated at Thr558, showed a similar CI to the WT controls (Fig. 5 B). Thus, dephosphorylation of moesin was shown to be a prerequisite for cell migration, whereas expressing moesin-T558D inhibited cell migration.

\section{Moesin suppresses RhoA, Rac, and Cdc42 through the inhibition of GEFs}

We next examined the potential mechanisms by which moesin regulates cell migration. Moesin regulates Rho GTPase activity (Speck et al., 2003). Thus, we examined the activity of three major Rho GTPases, RhoA, Rac, and Cdc42, in both 

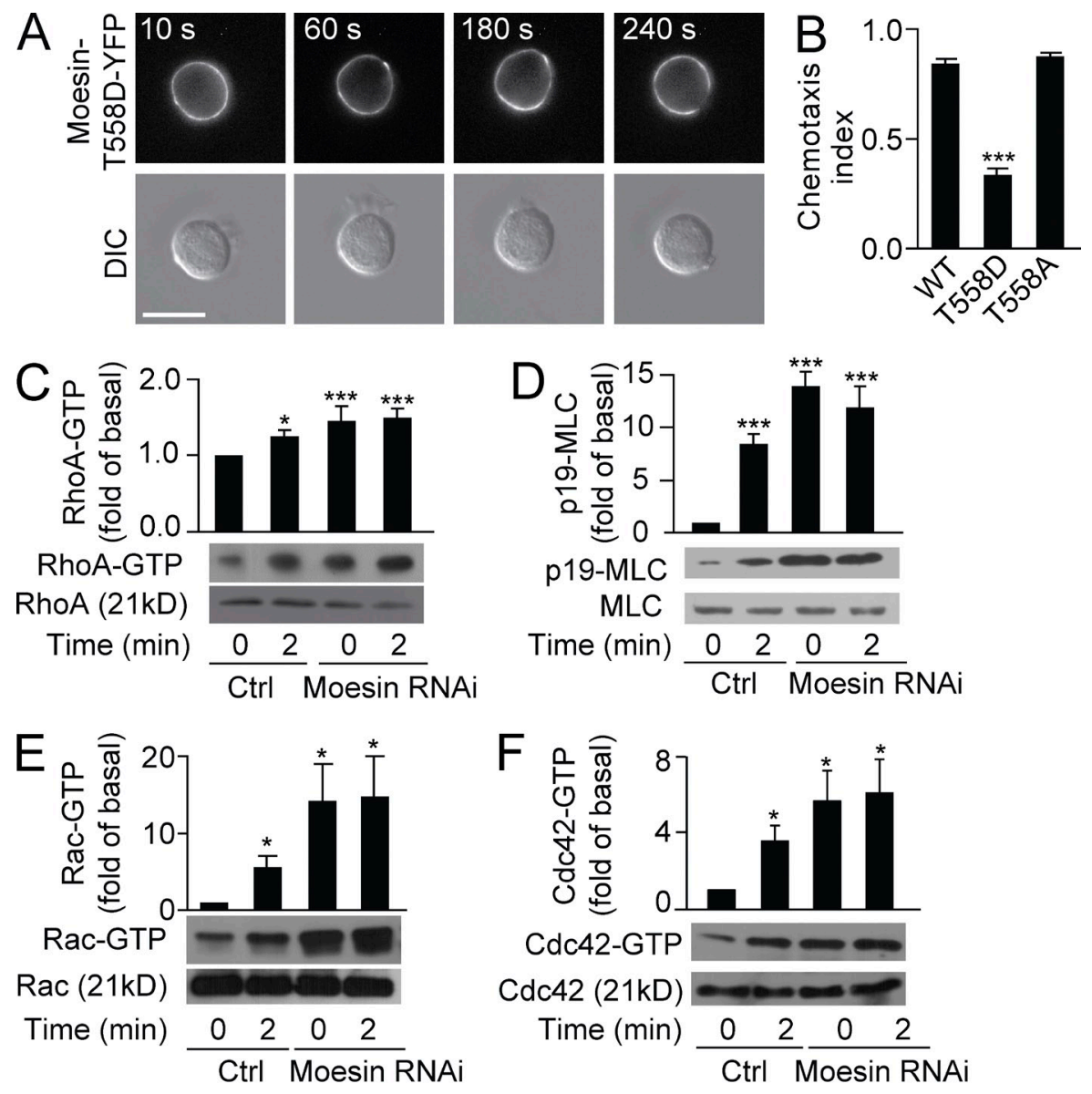

Cdc42-GTP

Cdc42 (21kD)

Time (min)
Figure 5. Moesin inhibits Rho, Rac, and Cdc42 activity. (A) HL60 cells ( $n>30)$ expressing moesin-T558D-YFP were stimulated for the indicated times with $100 \mathrm{nM}$ fMLF and visualized by fluorescence (top) and DIC microscopy (bottom). (B) HL60 cells expressing WT-moesin, moesin-T558D, or moesin-T558A were exposed to an fMLF gradient of $100 \mathrm{nM}$ ( $>30$ cells per condition), and $\mathrm{Cl}$ was calculated. ${ }^{* *}, \mathrm{P}<0.001$ compared with WT (Student's $t$ test). (C-F) Control and moesin RNAi cells were stimulated with $100 \mathrm{nM} \mathrm{fMLF}$ for 0 or 2 min. Expression of RhoA-GTP and total RhoA (C), p-MLC and total MLC (D), Rac-GTP and total Rac (E), and Cdc42-GTP and total Cdc42 (F) was measured by immunoblot. Graphs show quantification of immunoblot data. Results are shown relative to control cells at 0 min. ${ }^{*}, P<0.05 ;{ }^{* * *}, P<0.001$ compared with control (Student's $t$ test). (G) HL60 cells ( $n>30$ per group) expressing N-moesin-GFP were stimulated for the indicated times with $100 \mathrm{nM}$ fMLF and visualized using fluorescence (top) and DIC microscopy (bottom). (A and G) Bars, $10 \mu \mathrm{m}$. Data are representative of ( $A$ and $G$ and blots in $\mathrm{C}-\mathrm{F}$ ) or are compiled from three independent experiments $(B$ and graphs in $\mathrm{C}-\mathrm{F}$; mean and SEM in $\mathrm{B}-\mathrm{F}$ ).
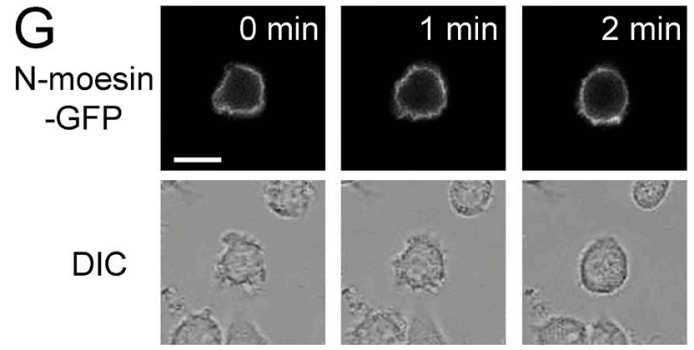

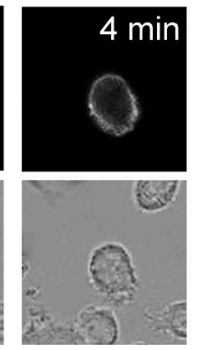

control and moesin RNAi-treated cells. Attractant stimulation (100 nM fMLF, $2 \mathrm{~min}$ ) increased RhoA-GTP (active form) levels by 1.3-fold over basal levels (Fig. 5 C). In moesin RNAi-treated cells, the basal level of RhoA-GTP was also increased by $\sim 1.5$-fold compared with the control and was not further increased after AMLF stimulation (Fig. 5 C). Therefore, moesin antagonized RhoA activity at the resting state. Similarly, p-MLC, Cdc42-GTP, and Rac-GTP were also substantially increased in moesin RNAi-treated cells, both before and after fMLF stimulation (Fig. 5, D-F). Thus, moesin maintained basal cell symmetry by inhibiting Rac, Rho, and Cdc42 activity.

We further examined how moesin inhibited the small Rho GTPases. As Rho GTPase activation requires GEFs, we tested the hypothesis that moesin interferes with GEFs on the cell membrane, preventing them from activating the Rho GTPases.
Vav1 mediates the radixin-dependent increase in Rac activity (Valderrama et al., 2012) and is required for neutrophil activation by the integrin receptor (Cremasco et al., 2008). We found that the $\mathrm{N}$ terminus (aa 1-310) but not $\mathrm{C}$ terminus (aa 457-577) of moesin bound the DH/PH domain of Vav1 (aa 160-550), the GEF domain known to activate Rac (Fig. 6 A). To determine whether $\mathrm{N}$-moesin inhibits the interaction of Rac with Vav1-DH/PH, we coexpressed FLAG-Rac with HA-Vav1-DH/PH in either the presence or absence of GFP$\mathrm{N}$-moesin. The Vav1-DH/PH fragment was pulled down with $\mathrm{Rac}$ in the absence of $\mathrm{N}$-moesin, whereas binding was significantly inhibited in the presence of N-moesin (Fig. $6 \mathrm{~B}$; $\mathrm{P}<0.05)$. Thus, moesin may inhibit $\mathrm{Rac}$ activation by reducing the interaction of $\mathrm{Rac}$ with the Vav1-DH/PH domain.

We next examined whether moesin inhibits RhoA and Cdc42 in a similar manner. PDZRhoGEF (PRG) has been 


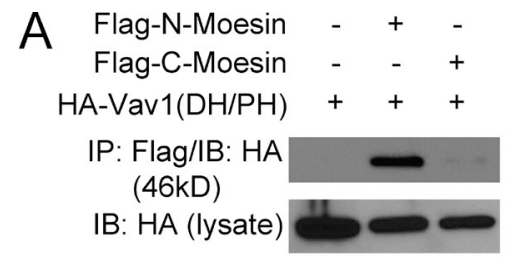

B

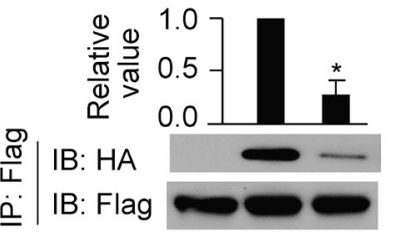

IB: HA (lysate) Flag-Rac $\mathrm{HA}-\mathrm{Vav} 1(\mathrm{DH} / \mathrm{PH})$ GFP-N-Moesin
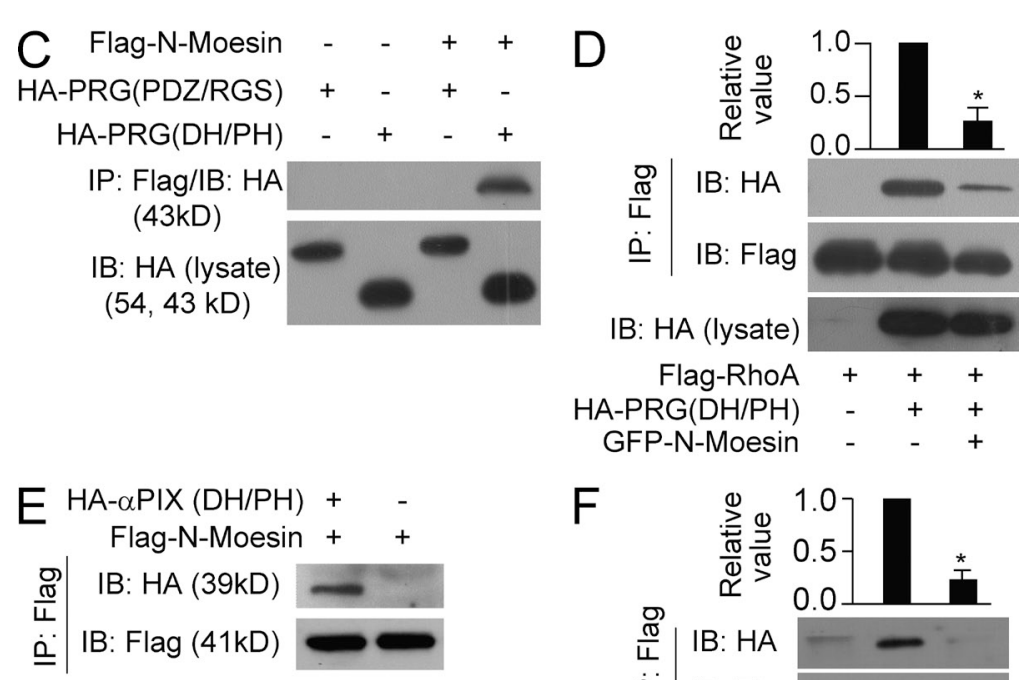

Figure 6. Moesin interacts with RhoGEFs. (A) The DH/PH fragment of Vav1 was immunoprecipitated with $\mathrm{N}$-moesin (aa 1-310) or C-moesin (aa 457-577). (B) Rac was pulled down with Vav1-DH/PH domain in the presence or absence of $\mathrm{N}$-moesin. (C) N-moesin was immunoprecipitated with the DH/PH domain or the PDZ/RGS domain of PRG. (D) RhoA was pulled down with PRG DH/PH domain in the presence or absence of $\mathrm{N}$-moesin. (E) N-moesin was immunoprecipitated with the DH/PH domain of $\alpha$ PIX. (F) $\mathrm{Cdc} 42$ was pulled down with the $\alpha \mathrm{PIX} D \mathrm{DH} / \mathrm{PH}$ domain in the presence or absence of $\mathrm{N}$-moesin. $\left(\mathrm{B}, \mathrm{D}\right.$, and $\mathrm{F}$ ) ${ }^{*}, \mathrm{P}<0.05$ (Student's $t$ test). Data are representative of (blots in $\mathrm{A}-\mathrm{F}$ ) or are compiled from three independent experiments (graphs in $B, D$, and $F$; mean and SEM in $B, D$, and F).

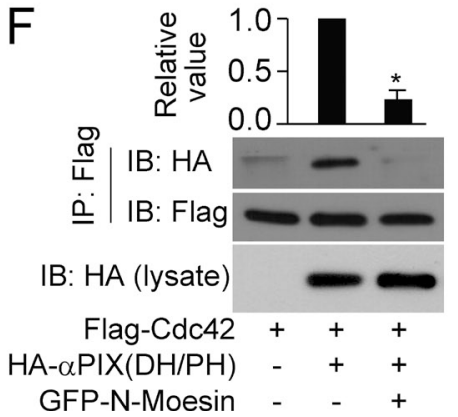

shown to activate RhoA in HL60 cells (Wong et al., 2007). We found that $\mathrm{N}$-moesin bound the $\mathrm{DH} / \mathrm{PH}$ domain of PRG and prevented RhoA binding to the domain (Fig. 6, $\mathrm{C}$ and D). Similarly, N-moesin blocked Cdc42 binding to the DH/PH domain of $\alpha$-PIX, a GEF for Cdc42 (Fig. 6, $\mathrm{E}$ and $\mathrm{F})$. Thus, at the basal stage, membrane-bound $\mathrm{N}$-moesin masked the DH/PH domain of RhoGEFs and prevented their interaction with and activation of Rho GTPases. Based on this finding, we surmised that overexpressing the $\mathrm{N}$-terminal domain of moesin would prevent the formation of neutrophil polarity and cell migration. We observed that the cells expressing GFP-N-moesin exhibited severe defects in both cell polarization and migration (Fig. 5 G).

\section{Knockdown of $\alpha$-PIX restores cell migration in moesin RNAi cells}

We next investigated whether increased Rho GTPase activity is responsible for the impaired polarization and migration observed in moesin knockdown cells. Moesin RNAi cells were treated with RNAi constructs specific for GEFs described above. Knockdown of $\alpha$-PIX in these moesin RNAi cells reduced the elevation of Cdc42 activity and rescued the migratory defects found in moesin knockdown cells (Fig. 7, A-C).
These $\alpha$-PIX and moesin double knockdown cells showed relatively stable polarity (Fig. 7 D), formed fewer multiple pseudopods (Fig. 7 D and Table S5), and exhibited a longer lifetime of pseudopods compared with moesin single knockdown cells (Fig. 7 E). Additionally, these cells migrated with fewer turns in an $\mathrm{fMLF}$ gradient (Fig. $7 \mathrm{~A}$ ) and showed significantly higher CI values than moesin RNAi cells $(0.84$ vs. $0.35, \mathrm{P}<0.001)$, and the CI was similar to that of control cells (Fig. 7 B).

Knockdown of Vav1 also partially rescued moesin knockdown phenotypes. The Vav1 and moesin double knockdown cells exhibited better polarization and CI values compared with moesin single knockdown cells though these parameters still inferior to those in normal control cells (Fig. 7, A-E).

\section{Myosin phosphatase mediates moesin dephosphorylation and initiates cell migration}

Moesin inactivates both frontness and backness signals in resting neutrophils through the inhibition of Rho GTPases, as described above. Hence, to undergo polarization and migration, cells must deactivate moesin-mediated inhibition and thereby initiate cell migration. We next addressed the mechanism responsible for breaking the symmetry and initiating cell migration. We focused on the role of myosin phosphatase, 
A
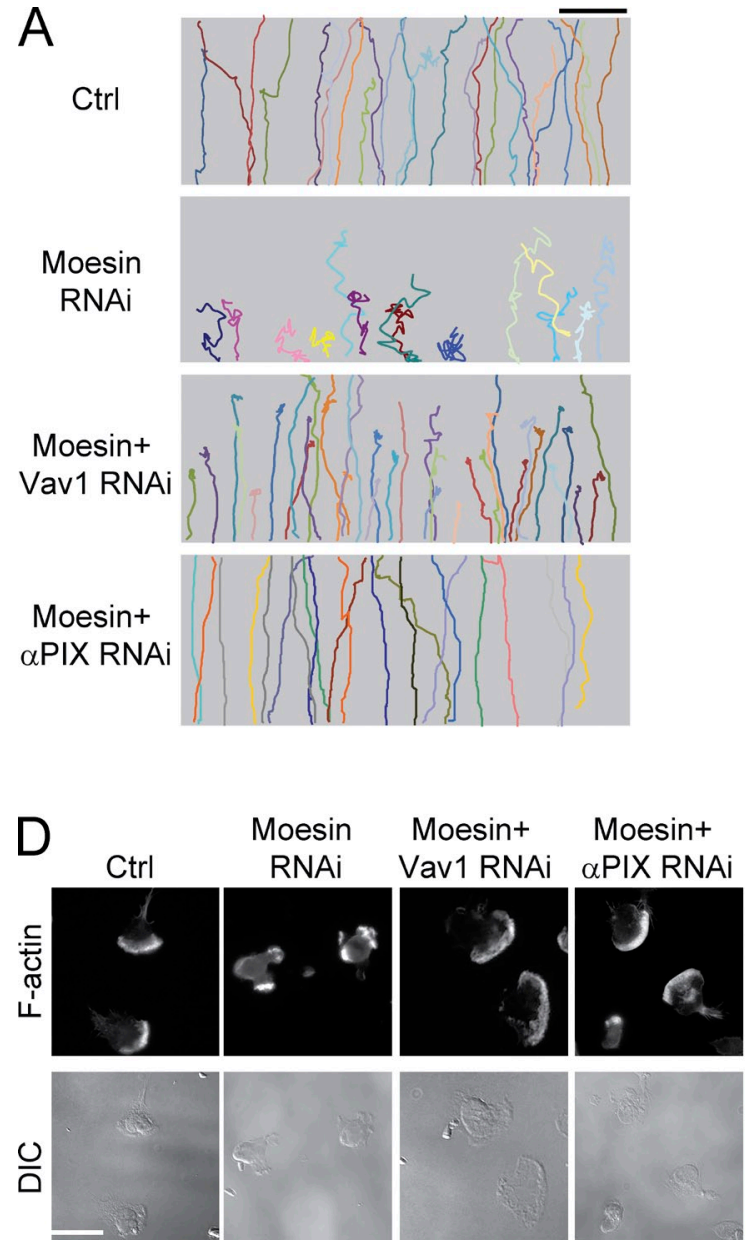
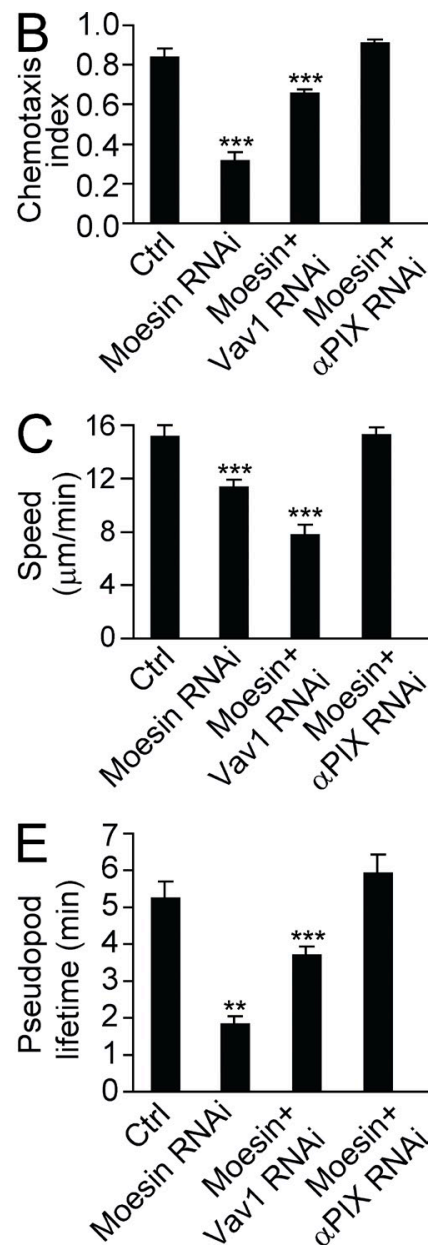

Figure 7. Knockdown of $\alpha$ PIX rescues cell migration in moesin-depleted cells. (A) Control, moesin RNAi, moesin + Vav1 RNAi, or moesin $+\alpha$ PIX RNAi cells were exposed to a 100-nM fMLF gradient. Each trace represents one individual cell ( $>30$ cells per condition). (B and C) Cells were treated as in A. $\mathrm{Cl}(\mathrm{B})$ and speed (C) were calculated. ${ }^{* *}, \mathrm{P}<$ 0.001 (Student's $t$ test). (D) Control, moesin RNAi, moesin + Vav1 RNAi, or moesin $+\alpha$ PIX RNAi cells were stimulated with FMLF and were visualized with F-actin (top) and DIC (bottom). $n>30$ cells per condition. Bars: (A) $100 \mu \mathrm{m}$; (D) $10 \mu \mathrm{m}$. (E) Cells were treated as in D. Pseudopod lifetime was calculated. ${ }^{* *}, \mathrm{P}<$ $0.01{ }^{* * *}, \mathrm{P}<0.001$ (Student's $t$ test). Data are representative of ( $A$ and $D$ ) or are compiled from three independent experiments $(B, C$, and $E ;$ mean and SEM in $B, C$ and $E)$. which dephosphorylates both moesin and MLC (Fukata et al., 1998). Both the catalytic subunit (PP1c) and the MBS of myosin phosphatase are coimmunoprecipitated with the Hem-1 complex, which organizes the neutrophil's leading edge (Weiner et al., 2006). We first confirmed PP1c localization to the leading edge by expressing YFP-tagged PP1c in HL60 cells. PP1cYFP localized to both the cytosol and the nucleus in the basal stage. A uniform concentration of AMLF (100 nM) induced the recruitment of PP1c-YFP to the cell periphery and subsequently to the leading edge in polarized cells (Fig. $8 \mathrm{~A}$; a time course of PP1 localization is shown in Table S2).

To determine whether PP1c recruitment to the leading edge mediates moesin dephosphorylation, we knocked down PP1c in HL60 cells via RNAi (Fig. 8 B). Knockdown of PP1c prevented the dephosphorylation of moesin but did not alter the basal level of p-moesin (Fig. 8 C). This finding indicated that PP1c was responsible for the AMLF-induced dephosphorylation of moesin. Next, we transiently expressed moesinYFP in PP1c knockdown cells to assess moesin translocation. In PP1c-depleted cells, moesin-YFP was membrane bound and showed little dissociation from the membrane. Transient ruffle protrusion was observed, but these ruffles retracted shortly (Fig. 8 D, top). Similar results were observed in MBS (the regulatory subunit of myosin phosphatase) knockdown cells (Fig. 8, B-D).

When control cells were exposed to an AMLF gradient, they migrated up the entire gradient (Fig. 9 A). PP1c RNAitreated cells also migrated, but with poor directionality (Fig. 9 A), and the CI was significantly lower in PP1 RNAitreated cells compared with controls $(0.26$ vs. $0.72, \mathrm{P}<0.01$; Fig. 9 B). The migration speed of PP1c RNAi-treated cells was also significantly decreased (11.5 vs. $18.4 \mu \mathrm{m} / \mathrm{min}, \mathrm{P}<$ 0.01; Fig. 9 C). Similar results were obtained in MBS RNAi cells (Fig. 9, A-C). Expression of the moesin-T558A mutant, but not WT moesin, partially restored cell migration in PP1c RNAi cells (Fig. 9, D and E). Collectively, our data indicate that inhibition of myosin phosphatase prevented moesin dephosphorylation and dissociation from cell membrane, thus causing unstable cell polarity and impaired cell migration.

\section{Myosin phosphatase is recruited} to the pseudopods by front signals

We next investigated how myosin phosphatase is activated and recruited to the leading edges during cell polarization. Previous studies have shown that the interaction of PP1c with MBS significantly enhances the myosin phosphatase activity 

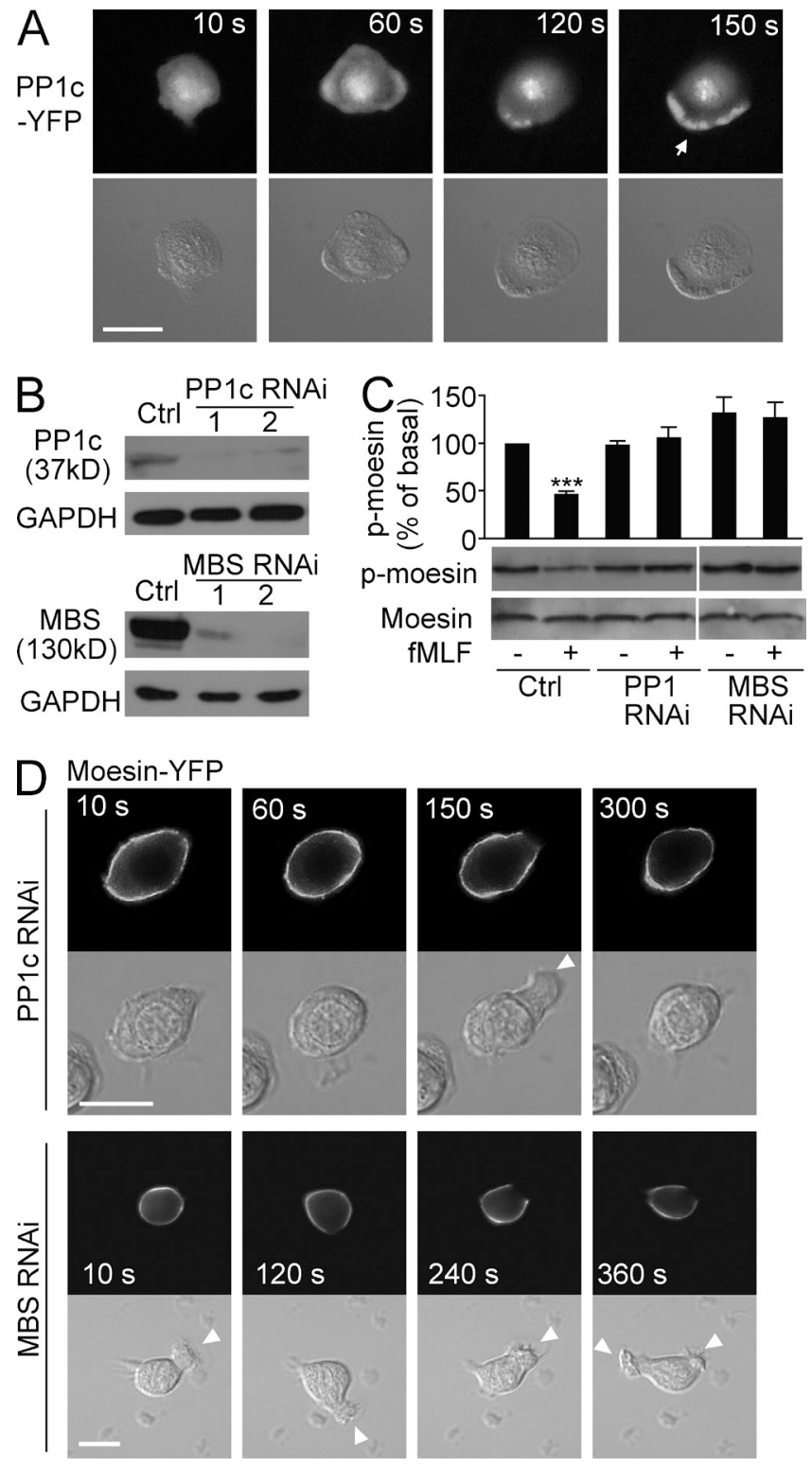

Figure 8. Myosin phosphatase releases moesin-mediated inhibition. (A) HL60 cells $(n>30)$ expressing PP1C-YFP were stimulated for the indicated times with $100 \mathrm{nM}$ fMLF and were visualized with fluorescence (top) and DIC microscopy (bottom). Arrow indicates the leading edge. (B) Expression of PP1c (top) or MBS (bottom) in control and PP1C RNAi cells or in control and MBS RNAi cells was measured by immunoblot. Two PP1c or MBS RNAi cell lines are shown. GAPDH was used as a loading control. (C) Control, PP1C, or MBS RNAi cells were stimulated with $100 \mathrm{nM}$ fMLF. Expression of p-moesin and total moesin was measured with immunoblot. Graph shows quantification of immunoblot data. Results are presented relative to maximum activation of $p$-moesin at 0 min. ${ }^{* *}, P<0.001$ compared with control without fMLF. (D) PP1c RNAi cells or MBS RNAi cells ( $n>30$ per group) expressing moesin-YFP were stimulated for the indicated times with $100 \mathrm{nM} \mathrm{fMLF}$ and were visualized with fluorescence (top) and DIC microscopy (bottom). Arrowheads indicate transient leading edges. ( $A$ and $D)$ Bars, $10 \mu \mathrm{m}$. Data are representative of $(A, B, D$, and blots in $C$ ) or are compiled from three independent experiments (graph in $C_{\text {; }}$ mean and SEM in C).
(Ichikawa et al., 1996; Terrak et al., 2004). We performed an immunoprecipitation analysis of the interaction between PP1c and MBS before and after stimulation. The interaction between PP1c and MBS was enhanced after PMLF stimulation (Fig. 9 F), suggesting that myosin phosphatase was activated after attractant stimulation. As myosin phosphatase interacts with Hem-1 (Weiner et al., 2006), we knocked down Hem-1 in HL60 cells and examined PP1c translocation. We observed that the recruitment of PP1c to the front was severely impaired in Hem-1 RNAi cells (Fig. 9 G), indicating the role of Hem-1 in recruiting PP1c to the leading edge. Therefore, the recruitment of PP1c to the leading edge depends on the frontness signals. We further validated this finding by inhibiting the Gi-mediated frontness signals with pertussis toxin (PTX). We found that $\mathrm{PP} 1 \mathrm{c}$ recruitment at the leading edge was blocked in PTX-treated cells (Fig. 9 G). Together these findings show that recruitment of PP1c to the front critically depends on Gi-mediated frontness signals.

\section{DISCUSSION}

We have demonstrated an essential role for moesin in regulating neutrophil polarization and directional sensing, both of which are crucial for neutrophils to locate invading pathogens. Deletion of moesin not only blocks neutrophil directionality toward invading bacteria but also diminishes neutrophilmediated microbial killing and inflammation. These findings expand the previous frontness-backness model (Xu et al., 2003), demonstrating that moesin functions as a symmetry-maintaining molecule that inhibits both frontness and backness signals in the resting state. Myosin phosphatase disrupts this inhibition to initiate cell polarization. After cell polarization, moesin localizes to the sides and posterior of cells to maintain the correct cell orientation while cells chase invading pathogens. Therefore, the maintenance of cell symmetry and orientation requires the same inhibitory mechanism exerted by moesin. In our new model, attractants from bacteria not only activate the frontness and backness pathways that are essential for pseudopod and uropod formation but also promote myosin phosphatase to release moesin-mediated inhibition at the would-be leading edge, thus initiating cell polarization.

Previous reaction-diffusion models assume the existence of a global inhibitor, but biochemical evidence of such an inhibitor is still lacking. Hence, concerns have been raised about whether such a global inhibitor exists, and new models without a global inhibition component have been proposed (Onsum and Rao, 2007). Here, we provide evidence that moesin inhibits frontness and backness signals and determines cell orientation but functions differently from the theoretical global inhibitor. First, moesin-mediated inhibition was not generated through localized activation. Instead, moesin was constitutively active in the resting state and was deactivated via localized activation upon stimulation. Second, moesin did not require diffusion to function because moesin was already membrane bound and active in the basal stage. This finding offers an alternative explanation for the observation 


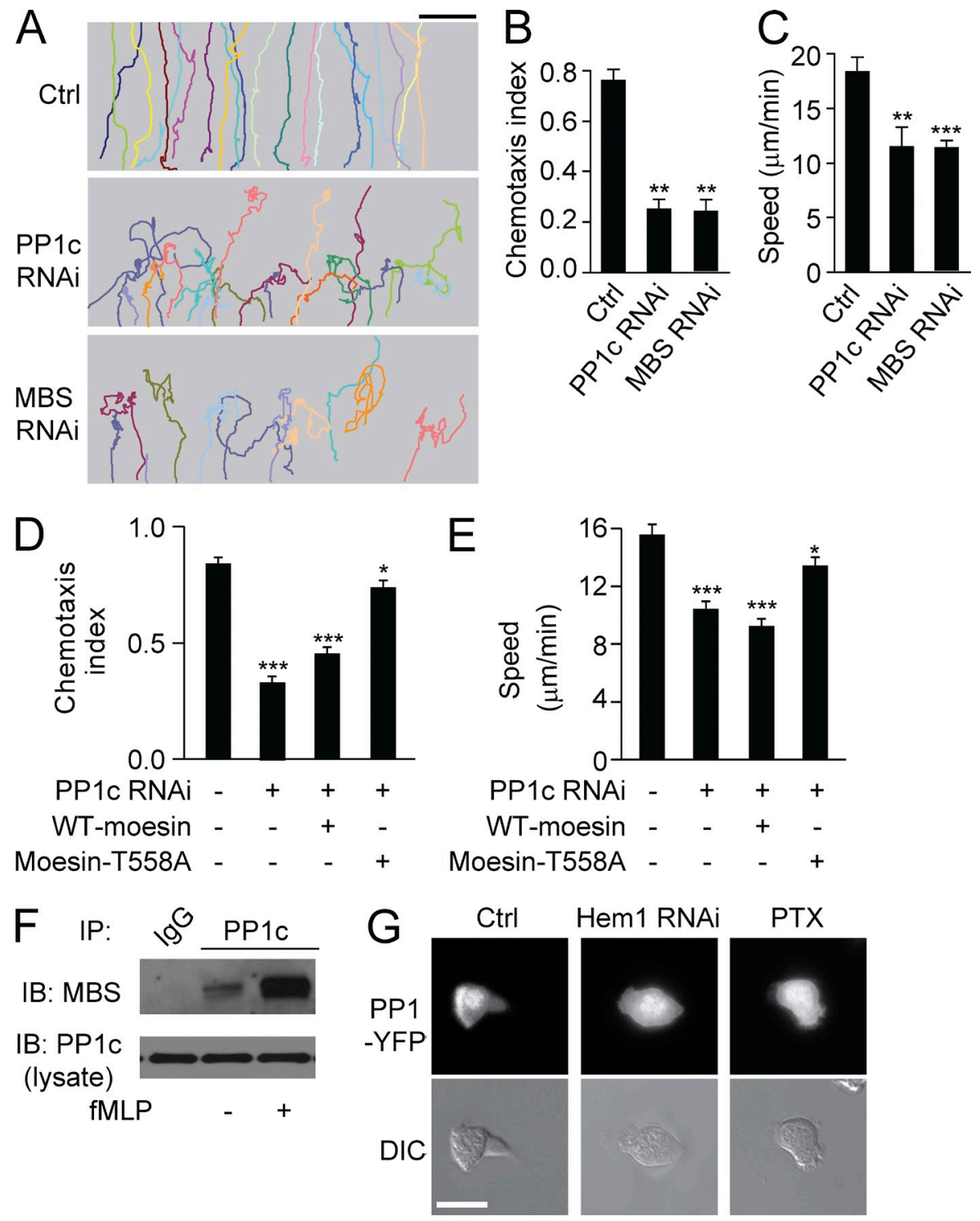

Figure 9. Myosin phosphatase is recruited to the leading edges by front signals. (A) Control, PP1c RNAi, or MBS RNAi cells were exposed to an fMLF gradient of $100 \mathrm{nM}$ (>30 cells per condition). Each trace represents the trajectory of one cell. (B and C) Cells were treated as in A. $\mathrm{Cl}(\mathrm{B})$ and migration speed (C) were calculated. ${ }^{*}, \mathrm{P}<0.01 ;{ }^{* * *}, \mathrm{P}<0.001$ compared with control (Student's $t$ test). (D and E) Control, PP1c RNAi, PP1c RNAi + WT-moesin, and PP1c RNAi + mosein-T558A cells were exposed to an fMLF gradient. Cl (D) and migration speed (E) were calculated. ${ }^{*}, \mathrm{P}<$ $0.01 i^{* * *}, P<0.001$ compared with control (Student's $t$ test). (F) PP1c was pulled down with MBS in the presence or absence of fMLF in HL60 cells. (G) HL60 cells ( $n>30$ per group) expressing PP1c-YFP were left untreated (left) or treated with Hem1 RNAi (middle) or PTX (right) in the presence of $100 \mathrm{nM}$ fMLF for $2 \mathrm{~min}$. Cells were visualized with fluorescence (top) and DIC microscopy (bottom). Bars: (A) $100 \mu m$; (G) $10 \mu m$. Data are representative of $(A, F$, and $G)$ or are compiled from three independent experiments ( $B-E$; mean and $S E M$ in $B-E)$.

that diffusion is not required for long-range inhibition as reported previously (Houk et al., 2012).

We demonstrated that moesin mediated symmetry in resting neutrophil by inhibiting Rac, RhoA, and Cdc42 activity. This inhibition was caused by moesin's role in preventing the GEF activation of Rho GTPases. Moesin may also regulate Rho GTPases by interacting with RhoGDIs (Hirao et al., 1996; Takahashi et al., 1997). Therefore, moesin likely interacts with RhoGDI and GEFs spatially and temporally to regulate Rho GTPase activities. After cell polarization, backness signals such as RhoA and MLC were activated at the trailing edge while moesin was also present. One possible mechanism that may explain this observation is that other GEFs, which are not inhibited by moesin, can mediate the activation of RhoA. For example, both p115RhoGEF and LAR G GEF are regulated by G12/13 and can activate RhoA (Hart et al., 1998; Fukuhara et al., 2000). We found that moesin did not inhibit RhoA binding to p115RhoGEF (unpublished data). We also observed that

moesin and MLC did not always overlap at the trailing edges (Fig. 3 A, left). Furthermore, the existence of both activators (e.g., GEFs) and inhibitors (e.g., moesin) for RhoA/MLC in the uropod may be responsible for the previously reported fluctuation of RhoA activity and the rear traction force (Wong et al., 2006; Shin et al., 2010), which are required for the efficient rear contraction.

We found that myosin phosphatase was recruited to the cell's leading edge and the recruitment depended on Hem-1and Gi-mediated frontness signals (Fig. 9). In this sense, myosin phosphatase is a key frontness molecule. Furthermore, our results showed that the initiation of cell polarization was mediated by the activation of myosin phosphatase. Upon attractant stimulation, myosin phosphatase translocated to the cell membrane and dephosphorylated moesin, releasing moesinmediated inhibition and enabling pseudopod protrusion. Importantly, removal of this phosphatase abolished cell protrusion and migration. Thus, in our new model, the initiation of cell 
migration is a function of counteracting moesin-mediated basal inhibition in resting neutrophils.

Although moesin is a crucial inhibitory signal responsible for cell migration, other inhibitory signals have also been reported. For example, the Erk-GRK2 signaling pathway can negatively regulate neutrophil migration (Liu et al., 2012). In other studies, blocking the activities of signaling agents such as the microtubule cytoskeleton (Xu et al., 2005) and calpain (Lokuta et al., 2003) was shown to enhance basal migration. Interestingly, inhibition of calpain increases Rac and Cdc42 activities (Lokuta et al., 2003), and removal of microtubules enhances RhoA activity (Xu et al., 2005), whereas inhibition of moesin increased the activity of all three Rho GTPases. Furthermore, microtubules and upstream regulators such as GSK3 $\beta$ also contribute to directional sensing in neutrophils (Xu et al., 2005, 2007). Therefore, it is possible that in a wellconserved response such as directed neutrophil migration, multiple inhibitors functioning together to provide the global inhibition is necessary for the correct cell orientation and location of pathogens. Together, our data suggest that moesin and myosin phosphatase mediate a novel regulatory pathway that is essential for the innate immune response of neutrophils, which may provide novel therapeutic targets for enhancing neutrophil migration and improving their bactericidal function in inflammatory diseases.

\section{MATERIALS AND METHODS}

Antibodies, reagents, and mice. Mouse monoclonal antibody against moesin and rabbit polyclonal antibodies against myosin IIA were from Sigma-Aldrich. Rabbit polyclonal antibodies against phosphorylated myosin light chain (Ser19) and moesin were purchased from Cell Signaling Technology. Rabbit polyclonal antibody against RhoA was purchased from Thermo Fisher Scientific. Mouse monoclonal antibody against GAPDH was from Proteintech. Rabbit polyclonal antibodies against HA were purchased from Signalway Antibody. Mouse monoclonal antibody against Flag and actin were from Beyotime Biotechnology. Mouse monoclonal antibody against GFP was purchased from Abgent. Human fibronectin was from BD. Bovine serum albumin was purchased from Amresco. Y-27632, Blebbistatin, DMSO, fMLF, protease inhibitor, and phosphatase inhibitor cocktails were from Sigma-Aldrich.

WT C57BL/6 mice were obtained from Charles River, and $\mathrm{Msn}^{-/ Y}$ mice were described previously (Doi et al., 1999). These genotypes have been backcrossed onto a C57BL/6 background for more than eight generations. The moesin gene is located on the $\mathrm{X}$ chromosome. Male hemizygous $\left(M s n^{-/ Y}\right)$ and littermate WT $\left(M s n^{+/ Y}\right)$ mice, $8-10 \mathrm{wk}$ of age, were used for experiments. Mice were bred and housed in pathogen-free conditions with access to food and water ad libitum in the Animal Care Facility. All experimental procedures were approved by the Animal Care Committee and Institutional Biosafety Committee of the University of Illinois, Chicago.

DNA constructs. The moesin, PP1, and MBS cDNAs were cloned from RT-PCR and then inserted into pEYFP- and flag-tagged vectors. For moesin RNAi knockdown, two pairs of sequences (\#1 and \#2, sequences Table S1) were used to make an shRNA expression cassette and then cloned into BamHI and XhoI restriction enzyme sites of pEN_hH1C plasmid (Invitrogen). By using the LR recombination reaction, shRNA expression cassette was inserted into lentiviral shRNA expression plasmid pDSL_hpUGIP and then co-transfected with psPAX2 and pMD2.G into the 293FT cell line to package lentivirus particles. Suspension was harvested $72 \mathrm{~h}$ after transfection and used to infected HL60 cells. Puromycin was used to screen the stable moesin RNAi cell line. For PP1c, MBS, and Vav1 RNAi knockdown, the lentiviruses were purchased from Santa Cruz Biotechnology, Inc. The sequences of siRNA of each protein are listed in Table S1.

Cell culture, transfection, and isolation of mouse neutrophils. Procedures for cultivation and differentiation of HL60 have been described previously (Xu et al., 2003). For transient transfections, differentiated HL60 cells (on day 6 after addition of DMSO) were washed once in RPMI-Hepes and suspended in the same medium to a final concentration of $10^{8} / \mathrm{ml}$. DNA was then added to the cells (30 $\mu \mathrm{g}$ PP1-YFP or MLC-YFP DNA), and the cellDNA mixture was incubated for $10 \mathrm{~min}$ at $25^{\circ} \mathrm{C}$, transferred to electroporation cuvettes, and subjected to an electroporation pulse on ice at $310 \mathrm{~V}, 1,180 \mu \mathrm{F}$, and low resistance. Transfected cells were allowed to recover for $10 \mathrm{~min}$ at $25^{\circ} \mathrm{C}$ and then transferred to $20 \mathrm{ml}$ complete medium. Subsequent assays were performed 4-6 h after transfection.

For bone marrow neutrophil isolation, mice were sacrificed, and femurs and tibias were taken out and flushed by a $27 \mathrm{G}$ needle with a $10-\mathrm{ml}$ syringe filled with calcium- and magnesium-free HBSS plus $0.1 \%$ BSA. Cells were then centrifuged and resuspended in HBSS. After filtering with a $40-\mu \mathrm{m}$ strainer, cells in $3 \mathrm{ml}$ HBSS were loaded onto a preprepared gradient solution ( $3 \mathrm{ml}$ NycoPrep on the top and $3 \mathrm{ml}$ of $72 \%$ Percoll on the bottom). The samples were centrifuged at $2,400 \mathrm{rpm}$ at room temperature for $20 \mathrm{~min}$ without break. The middle layer was collected and washed once in HBSS. To remove the red blood cells, $9 \mathrm{ml}$ of sterilized distilled water was added for $22 \mathrm{~s}$ and after $1 \mathrm{ml}$ of $10 \times$ PBS. Finally, the cells were collected and resuspended in HBSS or medium.

Modified LSR model and bacterial killing. Age-matched 8-10-wk-old WT and $\mathrm{Msn}^{-/ Y}$ mice were anaesthetized by i.p. injection of $100 \mathrm{mg} / \mathrm{kg}$ ketamine and $10 \mathrm{mg} / \mathrm{kg}$ xylazine, and the dorsal skin was shaved. $80 \mu \mathrm{g}$ LPS (O555:B5; Sigma-Aldrich) in $80 \mu \mathrm{l}$ PBS was injected into the right dorsum. As a negative control, $80 \mu \mathrm{l}$ PBS was injected into the left dorsum. $24 \mathrm{~h}$ later, $0.2 \mu \mathrm{g}$ TNF in $80 \mu \mathrm{l}$ PBS was injected into the same point on the right dorsum and $80 \mu \mathrm{l}$ PBS into the left. $24 \mathrm{~h}$ after TNF injection, the mice were sacrificed, and the interior of the dorsal skin was exposed for microscopic examination. The tissues were either fixed in $10 \%$ formalin for histological analysis with hematoxylin/eosin staining or frozen at $-80^{\circ} \mathrm{C}$ for MPO activity assay.

For bacterial killing, P. aeruginosa was subcultured at $37^{\circ} \mathrm{C}$ to logarithmic growth from an overnight culture. Bacteria were washed and suspended in PBS. $2 \times 10^{5}$ bacteria (in $40 \mu \mathrm{l}$ PBS) were i.t. injected into WT or $\mathrm{Msn}^{-/ Y}$ mice. After $8 \mathrm{~h}$, mouse lungs were collected aseptically after perfusion free of blood with PBS. The tissues were then homogenized with a tissue homogenizer under a vented hood. The lung homogenates were diluted 1:5, $5 \mu \mathrm{l}$ of each (plus $195 \mu \mathrm{l} \mathrm{PBS}$ ) was plated on LB agar and incubated for $14 \mathrm{~h}$ at $37^{\circ} \mathrm{C}$, and colonies were counted.

Lung tissue MPO activity. Lung tissue MPO activity was measured as described previously (Garrean et al., 2006). In brief, skin or lung tissues were flushed free of blood by PBS and homogenized in $50 \mathrm{mM}$ phosphate buffer (PB), $\mathrm{pH}$ 6.0. The homogenates were centrifuged at $40,000 \mathrm{~g}$ at $4^{\circ} \mathrm{C}$ for $30 \mathrm{~min}$. After discarding the supernatants, the pellets were resuspended in PB buffer containing $0.5 \%$ hexadecyl trimethylammonium bromide and vigorously vibrated to break up the large pellets. Then the pellets were frozen at $-70^{\circ} \mathrm{C}$ for $30 \mathrm{~min}$ and thawed at $37^{\circ} \mathrm{C}$. Subsequently, the pellets were homogenized and centrifuged a second time. Thereafter, the supernatants were used for MPO activity assay with a kinetics reading at $460 \mathrm{~nm}$ for $5 \mathrm{~min}$. Neutrophil sequestration was quantified as MPO activity normalized by tissue weight, and the data were presented as V-Max value/g tissue.

Cell migration assays. Live cells were imaged after stimulation either with a uniform concentration of $\mathrm{MLF}$ or a concentration gradient generated by an EZ-Taxiscan device or micropipette. EZ-Taxiscan assay was described previously (Liu et al., 2012). In brief, cells migrated over a $50 \mu \mathrm{g} / \mathrm{ml}$ fibronectincoated cover glass on a horizontal glass surface under a silicon chip. Cells were washed with RPMI, $25 \mathrm{mM}$ Hepes, pH 7.0, and $0.1 \%$ BSA and 
resuspended in RPMI, $25 \mathrm{mM}$ Hepes, and $0.1 \%$ BSA solution. Cells were loaded to the bottom of the chip, and chemoattractant was added to the top of the chip to generate a chemoattractant gradient. Cells migrated for $30 \mathrm{~min}$, and images were recorded with the EZ-Taxiscan software and then analyzed in Image (National Institutes of Health).

For micropipette assay, the gradient was generated by a point source of chemoattractant from a micropipette containing $10 \mu \mathrm{M}$ fMLF. Time-lapse video microscopy was performed as described previously (Xu et al., 2003). The cell migratory behaviors were recorded and analyzed in ImageJ.

For neutrophil peritoneal transmigration, mice were injected with $100 \mu \mathrm{l}$ saline or $10 \mathrm{nM}$ fMLF (in $100 \mu$ saline, i.p.). After $4 \mathrm{~h}$, peritoneal cavities of anesthetized mice were lavaged, and leukocytes were recovered. The total number of leukocytes was counted using a hemocytometer, and neutrophil counts were determined on $100-\mu \mathrm{l}$ cytospins stained with Diff-Quik and presented as a percentage of the total population.

Pull-down assays. RhoA, Cdc42, and Rac pull-down kits were purchased from Thermo Fisher Scientific, and assays were performed according to attached protocols. In brief, HL60 cells were stimulated with or without $100 \mathrm{nM}$ fMLF for $1 \mathrm{~min}$ and immediately lysed and centrifuged at 14,000 $\mathrm{g}$ for $10 \mathrm{~min}$. Equal amounts of the resulting supernatant fractions were incubated with either rhotekin RBD-agarose (which binds RhoA-GTP) or PBD-agarose (which binds Rac-GTP and Cdc42-GTP) for $2 \mathrm{~h}$ at $4{ }^{\circ} \mathrm{C}$, followed by washing three times with lysis buffer. Proteins binding to the beads were eluted in protein loading buffer and subjected to Western blot analysis using rabbit polyclonal antibody specific to RhoA, Cdc42, or Rac.

Immunoprecipitation and immunofluorescence. Immunoprecipitation and immunofluorescence were performed as described previously (Xu et al., 2008). Densitometry of bands on autoradiograms was performed with scanned x-ray films and the ImageJ program. Results of at least three independent experiments are represented as a bar graph using arbitrary units to compare the intensity of the bands.

Statistical analysis. Statistical comparisons were made using the two-tailed Student's $t$ test. Experimental values are reported as the mean \pm SEM. Differences in mean values were considered significant at $\mathrm{P}<0.05$.

Online supplemental material. The supplemental videos show HL60 cells left untreated (Video 1) and Y27632-treated (Video 2) or moesin RNAitreated (Video 3) HL60 cells migrating toward a point source of fMLF $(10 \mu \mathrm{M}$, from a micropipette). Table S1 shows siRNA sequences for RNAi knockdown. Table S2 shows the percentages of polarized HL60 cells stimulated with $\mathrm{AMLF}$ at the indicated times and distribution of moesin and MLC in uropod (Fig. $2 \mathrm{~A}$ ) and PP1c in pseudopod (Fig. $8 \mathrm{~A}$ ) in these polarized cells. Table S3 shows the percentages of polarized HL60 cells (left untreated or blebbistatin or Y27632 treated) stimulated with $\mathrm{MLLF}$ at the indicated times (Fig. 3 A) and distribution of moesin or MLC in uropod in these polarized cells. Table S4 shows the distribution of MLC to uropod in control or moesin RNAi-treated HL60 cells stimulated with AMLF at the indicated times (Fig. 3 C). Table S5 shows multiple pseudopod formation in control, moesin RNAi-, moesin + Vav1 RNAi-, or moesin + $\alpha$ PIX RNAi-treated HL60 cells stimulated with fMLF. Online supplemental material is available at http://www.jem.org/cgi/content/full/jem.20140508/DC1.

In memory of Dr. Graeme K. Carnegie.

We thank Drs. Henry R. Bourne, Orion Weiner (both from University of California, San Francisco, San Francisco, CA), and Xiaoping Du (University of Illinois, Chicago, Chicago, IL) and Yan Li (Chinese Academy of Sciences, Beijing, China) for helpful discussion.

This work was supported in part by grants from the US National Institutes of Health (HL095716, HL077806, and Al033503), Chinese Academic of Sciences (KSCXW-R-66), and Natural Science Foundation of China (30630037).

The authors declare no competing financial interests.
Submitted: 17 March 2014

Accepted: 23 December 2014

\section{REFERENCES}

Bretscher, A., K. Edwards, and R.G. Fehon. 2002. ERM proteins and merlin: integrators at the cell cortex. Nat. Rev. Mol. Cell Biol. 3:586-599. http://dx.doi.org/10.1038/nrm882

Brown, M.J., R. Nijhara, J.A. Hallam, M. Gignac, K.M. Yamada, S.L. Erlandsen, J. Delon, M. Kruhlak, and S. Shaw. 2003. Chemokine stimulation of human peripheral blood $\mathrm{T}$ lymphocytes induces rapid dephosphorylation of ERM proteins, which facilitates loss of microvilli and polarization. Blood. 102:3890-3899. http://dx.doi.org/10.1182/blood-2002-12-3807

Brozna, J.P. 1990. Shwartzman reaction. Semin. Thromb. Hemost. 16:326332. http://dx.doi.org/10.1055/s-2007-1002685

Cremasco, V., D.B. Graham, D.V. Novack, W. Swat, and R. Faccio. 2008. Vav/Phospholipase C $\gamma 2$-mediated control of a neutrophil-dependent murine model of rheumatoid arthritis. Arthritis Rheum. 58:2712-2722. http://dx.doi.org/10.1002/art.23757

Doi, Y., M. Itoh, S. Yonemura, S. Ishihara, H. Takano, T. Noda, and S. Tsukita. 1999. Normal development of mice and unimpaired cell adhesion/cell motility/actin-based cytoskeleton without compensatory upregulation of ezrin or radixin in moesin gene knockout. J. Biol. Chem. 274:2315-2321. http://dx.doi.org/10.1074/jbc.274.4.2315

Firtel, R.A., and C.Y. Chung. 2000. The molecular genetics of chemotaxis: sensing and responding to chemoattractant gradients. BioEssays. 22:603-615. http://dx.doi.org/10.1002/1521-1878(200007)22:7<603:: AID-BIES3>3.0.CO;2-\#

Fukata, Y., K. Kimura, N. Oshiro, H. Saya, Y. Matsuura, and K. Kaibuchi. 1998. Association of the myosin-binding subunit of myosin phosphatase and moesin: dual regulation of moesin phosphorylation by Rho-associated kinase and myosin phosphatase. J. Cell Biol. 141:409-418. http://dx.doi .org/10.1083/jcb.141.2.409

Fukuhara, S., H. Chikumi, and J.S. Gutkind. 2000. Leukemia-associated Rho guanine nucleotide exchange factor (LARG) links heterotrimeric G proteins of the $\mathrm{G}_{12}$ family to Rho. FEBS Lett. 485:183-188. http:// dx.doi.org/10.1016/S0014-5793(00)02224-9

Garrean, S., X.P. Gao, V. Brovkovych, J. Shimizu, Y.Y. Zhao, S.M. Vogel, and A.B. Malik. 2006. Caveolin-1 regulates NF-KB activation and lung inflammatory response to sepsis induced by lipopolysaccharide. J. Immunol. 177:4853-4860. http://dx.doi.org/10.4049/jimmunol.177.7.4853

Hart, M.J., X. Jiang, T. Kozasa, W. Roscoe, W.D. Singer, A.G. Gilman, P.C. Sternweis, and G. Bollag. 1998. Direct stimulation of the guanine nucleotide exchange activity of $\mathrm{p} 115 \mathrm{RhoGEF}$ by $\mathrm{G} \alpha_{13}$. Science. 280:2112-2114. http://dx.doi.org/10.1126/science.280.5372.2112

Hatzoglou, A., I. Ader, A. Splingard, J. Flanders, E. Saade, I. Leroy, S. Traver, S. Aresta, and J. de Gunzburg. 2007. Gem associates with Ezrin and acts via the Rho-GAP protein Gmip to down-regulate the Rho pathway. Mol. Biol. Cell. 18:1242-1252. http://dx.doi.org/10.1091/mbc.E06-06-0510

Hirao, M., N. Sato, T. Kondo, S. Yonemura, M. Monden, T. Sasaki, Y. Takai, S. Tsukita, and S. Tsukita. 1996. Regulation mechanism of ERM (ezrin/ radixin/moesin) protein/plasma membrane association: possible involvement of phosphatidylinositol turnover and Rho-dependent signaling pathway. J. Cell Biol. 135:37-51. http://dx.doi.org/10.1083/jcb.135.1.37

Houk, A.R., A. Jilkine, C.O. Mejean, R. Boltyanskiy, E.R. Dufresne, S.B. Angenent, S.J. Altschuler, L.F. Wu, and O.D. Weiner. 2012. Membrane tension maintains cell polarity by confining signals to the leading edge during neutrophil migration. Cell. 148:175-188. http:// dx.doi.org/10.1016/j.cell.2011.10.050

Ichikawa, K., K. Hirano, M. Ito, J. Tanaka, T. Nakano, and D.J. Hartshorne. 1996. Interactions and properties of smooth muscle myosin phosphatase. Biochemistry. 35:6313-6320. http://dx.doi.org/10.1021/bi960208q

Ivetic, A., and A.J. Ridley. 2004. Ezrin/radixin/moesin proteins and Rho GTPase signalling in leucocytes. Immunology. 112:165-176. http://dx.doi.org/ 10.1111/j.1365-2567.2004.01882.x

Kawano,Y.,Y. Fukata, N. Oshiro, M. Amano, T. Nakamura, M. Ito, F. Matsumura, M. Inagaki, and K. Kaibuchi. 1999. Phosphorylation of myosin-binding subunit (MBS) of myosin phosphatase by Rho-kinase in vivo. J. Cell Biol. 147:1023-1038. http://dx.doi.org/10.1083/jcb.147.5.1023 
Kolaczkowska, E., and P. Kubes. 2013. Neutrophil recruitment and function in health and inflammation. Nat. Rev. Immunol. 13:159-175. http:// dx.doi.org/10.1038/nri3399

Lee, J.H., T. Katakai, T. Hara, H. Gonda, M. Sugai, and A. Shimizu. 2004. Roles of p-ERM and Rho-ROCK signaling in lymphocyte polarity and uropod formation. J. Cell Biol. 167:327-337. http://dx.doi.org/ $10.1083 / \mathrm{jcb} .200403091$

Liu, X., B. Ma, A.B. Malik, H. Tang, T. Yang, B. Sun, G. Wang, R.D. Minshall, Y. Li, Y. Zhao, et al. 2012. Bidirectional regulation of neutrophil migration by mitogen-activated protein kinases. Nat. Immunol. 13:457-464. http://dx.doi.org/10.1038/ni.2258

Lokuta, M.A., P.A. Nuzzi, and A. Huttenlocher. 2003. Calpain regulates neutrophil chemotaxis. Proc. Natl. Acad. Sci. USA. 100:4006-4011. http:// dx.doi.org/10.1073/pnas.0636533100

Ma, L., C. Janetopoulos, L. Yang, P.N. Devreotes, and P.A. Iglesias. 2004 Two complementary, local excitation, global inhibition mechanisms acting in parallel can explain the chemoattractant-induced regulation of $\mathrm{PI}(3,4,5) \mathrm{P} 3$ response in dictyostelium cells. Biophys. J. 87:3764-3774. http://dx.doi.org/10.1529/biophysj.104.045484

Martinelli, S., E.J. Chen, F. Clarke, R. Lyck, S. Affentranger, J.K. Burkhardt, and V. Niggli. 2013. Ezrin/Radixin/Moesin proteins and flotillins cooperate to promote uropod formation in T cells. Front. Immunol. 4:84. http://dx.doi.org/10.3389/fimmu.2013.00084

Meinhardt, H. 1999. Orientation of chemotactic cells and growth cones: models and mechanisms. J. Cell Sci. 112:2867-2874.

Meinhardt, H. 2009. Models for the generation and interpretation of gradients. Cold Spring Harb. Perspect. Biol. 1:a001362. http://dx.doi.org/10.1101/ cshperspect.a001362

Meinhardt, H., and A. Gierer. 1974. Applications of a theory of biological pattern formation based on lateral inhibition. J. Cell Sci. 15:321-346.

Meinhardt, H., and A. Gierer. 2000. Pattern formation by local self-activation and lateral inhibition. BioEssays. 22:753-760.http://dx.doi.org/10.1002/ 1521-1878(200008)22:8<753::AID-BIES9>3.0.CO;2-Z

Narang, A. 2006. Spontaneous polarization in eukaryotic gradient sensing: a mathematical model based on mutual inhibition of frontness and backness pathways. J. Theor. Biol. 240:538-553. http://dx.doi.org/10 $.1016 /$ j.jtbi.2005.10.022

Onsum, M., and C.V. Rao. 2007. A mathematical model for neutrophil gradient sensing and polarization. PLOS Comput. Biol. 3:e36. http:// dx.doi.org/10.1371/journal.pcbi.0030036

Parent, C.A., and P.N. Devreotes. 1999. A cell's sense of direction. Science. 284:765-770. http://dx.doi.org/10.1126/science.284.5415.765

Qian, F., J. Deng, N. Cheng, E.J. Welch, Y. Zhang, A.B. Malik, R.A. Flavell, C. Dong, and R.D. Ye. 2009. A non-redundant role for MKP5 in limiting ROS production and preventing LPS-induced vascular injury. EMBO J. 28:2896-2907. http://dx.doi.org/10.1038/emboj.2009.234

Reczek, D., M. Berryman, and A. Bretscher. 1997. Identification of EBP50: A PDZ-containing phosphoprotein that associates with members of the ezrin-radixin-moesin family. J. Cell Biol. 139:169-179. http://dx.doi.org/ 10.1083/jcb.139.1.169

Serrador, J.M., J.L. Alonso-Lebrero, M.A. del Pozo, H. Furthmayr, R. SchwartzAlbiez, J. Calvo, F. Lozano, and F. Sánchez-Madrid. 1997. Moesin interacts with the cytoplasmic region of intercellular adhesion molecule-3 and is redistributed to the uropod of T lymphocytes during cell polarization. J Cell Biol. 138:1409-1423. http://dx.doi.org/10.1083/jcb.138.6.1409

Shin, M.E., Y. He, D. Li, S. Na, F. Chowdhury, Y.C. Poh, O. Collin, P. Su, P. de Lanerolle, M.A. Schwartz, et al. 2010. Spatiotemporal organization, regulation, and functions of tractions during neutrophil chemotaxis. Blood. 116:3297-3310. http://dx.doi.org/10.1182/blood-2009-12-260851

Speck, O., S.C. Hughes, N.K. Noren, R.M. Kulikauskas, and R.G. Fehon. 2003. Moesin functions antagonistically to the Rho pathway to maintain epithelial integrity. Nature. 421:83-87. http://dx.doi.org/10.1038/ nature 01295

Swaney, K.F., C.H. Huang, and P.N. Devreotes. 2010. Eukaryotic chemotaxis: a network of signaling pathways controls motility, directional sensing, and polarity. Annu. Rev. Biophys. 39:265-289. http://dx.doi.org/ 10.1146/annurev.biophys.093008.131228

Takahashi, K., T. Sasaki, A. Mammoto, K. Takaishi, T. Kameyama, S. Tsukita, and Y. Takai. 1997. Direct interaction of the Rho GDP dissociation inhibitor with ezrin/radixin/moesin initiates the activation of the Rho small G protein. J. Biol. Chem. 272:23371-23375. http:// dx.doi.org/10.1074/jbc.272.37.23371

Terrak, M., F. Kerff, K. Langsetmo, T. Tao, and R. Dominguez. 2004. Structural basis of protein phosphatase 1 regulation. Nature. 429:780784. http://dx.doi.org/10.1038/nature02582

Tolias, K.F., J.H. Hartwig, H. Ishihara, Y. Shibasaki, L.C. Cantley, and C.L. Carpenter. 2000. Type I $\alpha$ phosphatidylinositol-4-phosphate 5-kinase mediates Rac-dependent actin assembly. Curr. Biol. 10:153-156. http://dx.doi.org/10.1016/S0960-9822(00)00315-8

Turing, A.M. 1952. The chemical basis of morphogenesis. Philosophical Transactions B. 237:37-72. http://dx.doi.org/10.1098/rstb.1952.0012

Valderrama, F., S. Thevapala, and A.J. Ridley. 2012. Radixin regulates cell migration and cell-cell adhesion through Rac1. J. Cell Sci. 125:33103319. http://dx.doi.org/10.1242/jcs.094383

Weiner, O.D., M.C. Rentel, A. Ott, G.E. Brown, M. Jedrychowski, M.B Yaffe, S.P. Gygi, L.C. Cantley, H.R. Bourne, and M.W. Kirschner. 2006. Hem-1 complexes are essential for Rac activation, actin polymerization, and myosin regulation during neutrophil chemotaxis. PLoS Biol. 4:e38. http://dx.doi.org/10.1371/journal.pbio.0040038

Wong, K., O. Pertz, K. Hahn, and H. Bourne. 2006. Neutrophil polarization: spatiotemporal dynamics of RhoA activity support a self-organizing mechanism. Proc. Natl. Acad. Sci. USA. 103:3639-3644. http://dx.doi.org/10 $.1073 /$ pnas. 0600092103

Wong, K., A. Van Keymeulen, and H.R. Bourne. 2007. PDZRhoGEF and myosin II localize RhoA activity to the back of polarizing neutrophil-like cells. J. Cell Biol. 179:1141-1148. http://dx.doi.org/10.1083/ jcb.200706167

Xu, J., F. Wang, A. Van Keymeulen, P. Herzmark, A. Straight, K. Kelly, Y. Takuwa, N. Sugimoto, T. Mitchison, and H.R. Bourne. 2003. Divergent signals and cytoskeletal assemblies regulate self-organizing polarity in neutrophils. Cell. 114:201-214. http://dx.doi.org/10.1016/ S0092-8674(03)00555-5

Xu, J., F. Wang, A. Van Keymeulen, M. Rentel, and H.R. Bourne. 2005. Neutrophil microtubules suppress polarity and enhance directional migration. Proc. Natl. Acad. Sci. USA. 102:6884-6889. http://dx.doi.org/10 $.1073 /$ pnas. 0502106102

Xu, J., A. Van Keymeulen, N.M. Wakida, P. Carlton, M.W. Berns, and H.R. Bourne. 2007. Polarity reveals intrinsic cell chirality. Proc. Natl. Acad. Sci. USA. 104:9296-9300. http://dx.doi.org/10.1073/pnas.0703153104

Xu, J., X.P. Gao, R. Ramchandran, Y.Y. Zhao, S.M. Vogel, and A.B. Malik. 2008. Nonmuscle myosin light-chain kinase mediates neutrophil transmigration in sepsis-induced lung inflammation by activating beta 2 integrins. Nat. Immunol. 9:880-886. http://dx.doi.org/10.1038/ni.1628

Yonemura, S., M. Hirao, Y. Doi, N. Takahashi, T. Kondo, S. Tsukita, and S. Tsukita. 1998. Ezrin/radixin/moesin (ERM) proteins bind to a positively charged amino acid cluster in the juxta-membrane cytoplasmic domain of CD44, CD43, and ICAM-2. J. Cell Biol. 140:885-895. http://dx.doi.org/10.1083/jcb.140.4.885

Yoshinaga-Ohara, N., A. Takahashi, T. Uchiyama, and M. Sasada. 2002. Spatiotemporal regulation of moesin phosphorylation and rear release by Rho and serine/threonine phosphatase during neutrophil migration. Exp. Cell Res. 278:112-122. http://dx.doi.org/10.1006/excr.2002.5571 